\title{
Integrating morphological and molecular approaches for characterizing four species of Dactylogyrus (Monogenea: Dactylogyridae) from Moroccan cyprinids, with comments on their host specificity and phylogenetic relationships
}

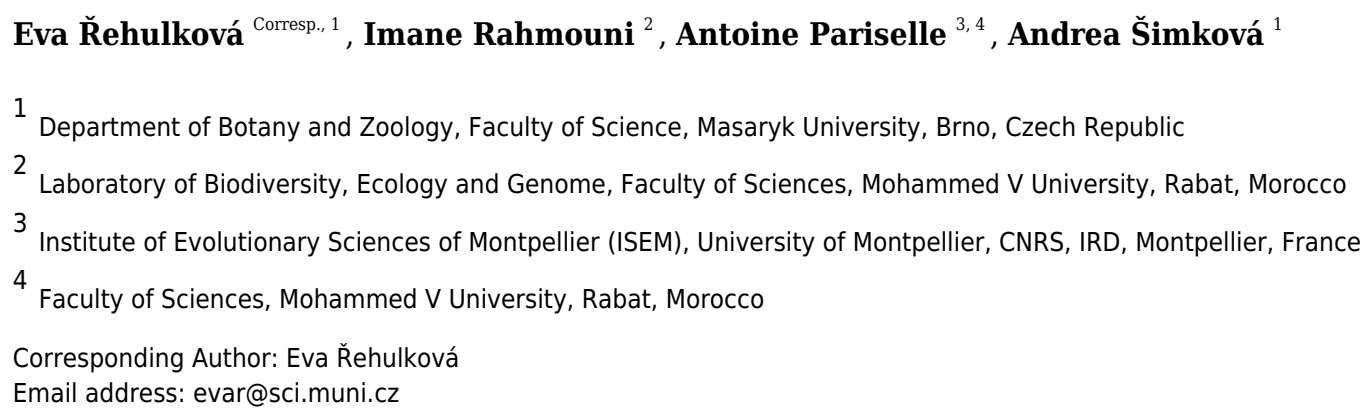

Cyprinid fishes are known to harbour highly host-specific gill-associated parasites of Dactylogyrus. High similarity in the morphology of sclerotized structures among Dactylogyrus species, especially those parasitizing congeneric cyprinoids, makes their identification difficult. In this paper, four previously known species of Dactylogyrus are characterized and illustrated under a reliable taxonomic framework integrating morphological and molecular evidence, and their phylogenetic relationships are investigated using molecular data. The species are as follows: $D$. borjensis from Luciobarbus zayanensis; $D$. draaensis from Luciobarbus lepineyi; $D$. ksibii from Luciobarbus ksibi and Luciobarbus rabatensis; and D. marocanus from Carasobarbus fritschii, L. ksibi, L. zayanensis and Pterocapoeta maroccana. Our results revealed intraspecific genetic variability among specimens of $D$. ksibii collected from two different hosts and geographically distant basins. Phylogenetic reconstruction showed that Dactylogyrus spp. parasitizing Moroccan cyprinids are representatives of three main lineages corresponding to morphological differences and host specificity. Our records of $D$. marocanus on $L$. zayanensis and $P$. maroccana increase the range of available host species i.e. eight species of four cyprinid genera representing two phylogenetic lineages (i.e. Barbinae and Torinae). 
1 Integrating morphological and molecular approaches for characterizing four

2 species of Dactylogyrus (Monogenea: Dactylogyridae) from Moroccan

3 cyprinids, with comments on their host specificity and phylogenetic

4 relationships

5

6 Eva Řehulková ${ }^{1}$, Imane Rahmouni ${ }^{2}$, Antoine Pariselle ${ }^{2,3}$ and Andrea Šimková ${ }^{1}$

7

$8 \quad{ }^{1}$ Department of Botany and Zoology, Faculty of Science, Masaryk University, Brno, Czech

9 Republic

10 2Laboratory of Biodiversity, Ecology and Genome, Faculty of Sciences, Mohammed V

11 University in Rabat, Morocco

12 '3SEM, University of Montpellier, CNRS, IRD, Montpellier, France

13

14 Corresponding Author:

15 Eva Řehulková

16 Kotlářská 2, Brno, 61137, Czech Republic

17 Email address: evar@sci.muni.cz

18

19

20

21

22 


\section{Abstract}

24 Cyprinid fishes are known to harbour highly host-specific gill-associated parasites of

25 Dactylogyrus. High similarity in the morphology of sclerotized structures among Dactylogyrus

26 species, especially those parasitizing congeneric cyprinoids, makes their identification difficult.

27 In this paper, four previously known species of Dactylogyrus are characterized and illustrated

28 under a reliable taxonomic framework integrating morphological and molecular evidence, and

29 their phylogenetic relationships are investigated using molecular data. The species are as

30 follows: D. borjensis from Luciobarbus zayanensis; D. draaensis from Luciobarbus lepineyi; D.

31 ksibii from Luciobarbus ksibi and Luciobarbus rabatensis; and D. marocanus from

32 Carasobarbus fritschii, L. ksibi, L. zayanensis and Pterocapoeta maroccana. Our results

33 revealed intraspecific genetic variability among specimens of $D$. ksibii collected from two

34 different hosts and geographically distant basins. Phylogenetic reconstruction showed that

35 Dactylogyrus spp. parasitizing Moroccan cyprinids are representatives of three main lineages

36 corresponding to morphological differences and host specificity. Our records of D. marocanus

37 on L. zayanensis and P. maroccana increase the range of available host species i.e. eight species

38 of four cyprinid genera representing two phylogenetic lineages (i.e. Barbinae and Torinae).

40 Introduction

41 Species of Dactylogyrus Diesing, 1850 are ectoparasitic flatworms (Monogenea,

42 Platyhelminthes) occurring mainly on the gills of cyprinid fishes. With more than 900 nominal

43 species, Dactylogyrus represents the largest helminth genus (Gibson et al., 1996). Recent studies

44 on northwest African cyprinids have shown that the biodiversity of this fish group is higher than

45 previously estimated (e.g. Brahimi et al., 2018; Casal-López et al., 2015; Doadrio et al., 2016; 
46 Doadrio, Casal-López \& Perea, 2016). In Morocco, 20 species belonging to four genera (i.e.

47 Carasobarbus Karaman, 1971; Labeobarbus Rüppel, 1835; Luciobarbus Heckel, 1843 and

48 Pterocapoeta Günther, 1902) are currently considered valid (Fricke, Eschmeyer \& Van der Laan, 49 2020). Among these, Luciobarbus is the most diverse, with 15 species, some being only recently 50 described (Brahimi et al., 2018; Casal-López et al., 2015; Doadrio et al., 2016; Doadrio, Casal51 López \& Perea, 2016). Descriptions of the new species may indicate that the diversity of their 52 host-specific parasites, such as monogeneans of Dactylogyrus, is currently underestimated. To 53 date, 17 Dactylogyrus spp. parasitizing 16 cyprinid species of three genera (Carasobarbus, 54 Labeobarbus and Luciobarbus) have been recorded in Morocco. Of these, 11 species are restricted to a single host species, five occur on two to six species belonging to one host genus and one species parasitizes species of three host genera (El Gharbi, Birgi \& Lambert, 1994;

57 Rahmouni et al., 2017). In 2015, a survey was initiated to determine the diversity of Dactylogyrus species parasitizing Moroccan cyprinids. A total of 13 cyprinid species were examined and 13 species of Dactylogyrus were collected and prepared for morphological and molecular analysis. The first

61 paper stemming from this investigation included descriptions of four new Dactylogyrus species infesting three species of northern Moroccan Luciobarbus (Rahmouni et al., 2017). This study also demonstrated that an integrated morphological and molecular approach to species identification/description can reveal the presence of morphologically indistinguishable, but genetically distinct, species (or cryptic species) within Dactylogyrus. Rahmouni et al. (2017) reported two cryptic species (Dactylogyrus benhoussai and Dactylogyrus varius forma vulgaris) parasitizing allopatric species of Luciobarbus (L. yahyaouii [syn. L. moulouyensis] and L. maghrebensis, respectively). On the other hand, they also identified three morphologically 
69 distinct, but genetically identical, forms of D. varius, demonstrating the usefulness of molecular

70 markers for documenting levels of intraspecific morphological variability or, in extreme cases, to

71 demonstrate that two or more monogenean morphospecies (morphotypes) represent a single

72 species.

73 More recently, Šimková et al. (2017) used 10 species of Dactylogyrus parasitizing Moroccan

74 cyprinids to infer potential historical contacts between northwest African, European and Asian

75 cyprinid faunas. Using phylogenetic reconstruction, they suggested that Dactylogyrus species

76 infecting Moroccan species of Carasobarbus were phylogenetically closely related to some

77 Dactylogyrus spp. parasitizing Iberian Luciobarbus spp. and shared a common ancestor with

78 southern and southeast Asian Labeonini hosts, while Dactylogyrus species infecting Moroccan

79 Luciobarbus spp. formed a large group together with Dactylogyrus species parasitizing European

80 Luciobarbus (including some Iberian and two known Balkan species), Barbus and leuciscid

81 hosts.

82 The present paper is a continuation of our research dealing with Dactylogyrus species from

83 Moroccan cyprinids. Herein, an effort is made to characterize and illustrate four previously

84 known species of Dactylogyrus under a reliable taxonomic framework integrating morphological

85 and molecular evidence and their phylogenetic relationships investigated using molecular data.

86

\section{Materials \& Methods}

88 Fish sampling

89 Two hundred specimens of six cyprinid species, namely Carasobarbus fritschii (Günther, 1874);

90 Luciobarbus ksibi (Boulenger, 1905); Luciobarbus lepineyi (Pellegrin, 1939); Luciobarbus

91 rabatensis Doadrio, Perea \& Yahyaoui, 2015; Luciobarbus zayanensis Doadrio, Casal-López \& 
92 Yahyaoui, 2016; and Pterocapoeta maroccana Günther, 1902, were captured by means of gill

93 nets or electro-fishing from eight localities in Morocco (Fig. 1, Table 1). The scientific names

94 and classification of fishes used are those provided in Fricke, Eschmeyer \& Van der Laan

95 (2020); names used in the original description are retained in square brackets as synonyms. Live

96 fishes were kept in aerated holding tanks until processed for parasitological examination. The

97 research was approved by the Ethics Committee of Masaryk University (approval number

98 CZ01302). Field experiments were approved by the Haut Commissairiat aux Eaux et Forêts et à

99 la Lutte contre la Désertification (Ministère de l'Agriculture, de la Pêche Maritime, du

100 Développement Rural et des Eaux et Forêts, Royaume du Maroc) ( ${ }^{\circ} 62$

101 HCEFLCD/DLCDPN/CPC/PPC).

102

103

\section{Parasite collection and fixation}

104 Fishes were sacrificed by severing the spinal cord, after which the gill arches were removed via 105 dorsal and ventral section and examined for monogeneans using a stereomicroscope. Specimens of Dactylogyrus were detached from the gills using fine needles and prepared following

107 Řehulková (2018). Monogeneans, fixed with a mixture of glycerine and ammonium picrate

108 (GAP) (Malmberg, 1957), were observed under an Olympus BX51 microscope equipped with

109 phase contrast optics. Specimens were measured using ImageJ software (available at:

110 http://rsb.info.nih.gov/ij/) following Řehulková, Benovics \& Šimková (2020). Measurements, all

111 in micrometers, are expressed as the mean followed in parentheses by the range and number $(n)$

112 of structures measured. Numbering of hook pairs was adopted from Mizelle (1936). The male

113 copulatory organ is henceforth abbreviated to MCO. Voucher specimens of monogeneans

114 collected in the present study were deposited at the Muséum National d'Histoire Naturelle 
115 (MNHN), Paris, France and the Institute of Parasitology of the Czech Academy of Sciences

116 (IPCAS), České Budějovice, Czech Republic as indicated in the respective species accounts.

118 DNA isolation, amplification and sequencing

119 To guarantee identification of parasites collected for molecular analysis, specimens collected for 120 DNA extraction were bisected into two parts, with one part transferred to an Eppendorf tube 121 containing ethanol (95\%) to preserve the DNA and the second half mounted in GAP for species 122 identification. Individual parasites were dried using a vacuum centrifuge. Genomic DNA was 123 extracted using the DNEasy extraction kit (Qiagen) following the manufacturer's instructions, 124 the extracted DNA being concentrated to a final volume of $80 \mu 1$. Partial $18 \mathrm{~S}$ rDNA and the entire 125 ITS1 region were amplified using the primers S1 (5'-ATTCCGATAACGAACGAGACT-3') and 126 IR8 (5'-GCTAGCTGCGTTCTTCATCGA-3'), which anneal to the 18S and 5.8S rDNA 127 sections, respectively (Šimková et al., 2003). PCR was carried out following the protocol and 128 conditions described by Rahmouni et al. (2017). Partial 28S rDNA was amplified using the 129 following primers: forward C1 (5'-ACCCGCTGAATTTAAGCA-3') and reverse D2 (5'130 TGGTCCGTGTTTCAAGAC-3') (Hassouna, Michot \& Bachellerie, 1984). PCR was performed 131 following Rahmouni et al. (2017). Visualization, purification and sequencing of PCR products 132 followed the methodology described in Rahmouni et al. (2017).

133

\section{Sequence alignment and phylogenetic analysis}

135 The DNA sequences obtained were analyzed using Sequencher software (Gene Codes Corp.).

136 All sequences were aligned using Clustal W multiple alignments (Thompson, Higgins \& Gibson, 137 1994) running in BioEdit version 7.2.5 (Hall, 1999). Genetic distances for each molecular 
138 marker (28S rDNA, 18S rDNA and ITS1), representing uncorrected p-distances between

139 sequences of the different Moroccan species reported herein, were calculated using MEGA 7

140 (Tamura et al., 2013) to express interspecific or intraspecific variability. For phylogenetic

141 analyses, all Moroccan representatives of Dactylogyrus parasitizing cyprinids with available

142 sequence data (i.e. nine Dactylogyrus spp. from Luciobarbus and four species of Dactylogyrus

143 from C. fritschii) were included in this study. The four remaining species previously reported to

144 parasitize Moroccan cyprinids (i.e. D. guirensis El Gharbi, Birgi \& Lambert, 1994, D. ksibioides

145 El Gharbi, Birgi \& Lambert, 1994, D. oumiensis El Gharbi, Birgi \& Lambert, 1994, and

146 Dactylogyrus reinii El Gharbi, Birgi \& Lambert, 1994) were not included in the analyses due to

147 missing recent records of these species and the associated absence of their DNA sequences. The

148 majority of Dactylogyrus species (i.e. eleven Dactylogyrus species) parasitizing European

149 species of Barbus and Luciobarbus were also included in the phylogenetic analyses. The

150 phylogenetic analysis was performed using unambiguous alignment of combined sequences (28S

151 rDNA, 18S rDNA and ITS1), with gaps and ambiguously aligned regions removed from the

152 alignment using GBlocks version 0.91 (Talavera \& Castresana, 2007). Phylogenetic analysis was

153 performed using the maximum likelihood (ML) and Bayesian inference (BI) approaches in

154 RAxML (Stamatakis, 2014) and MrBayes version 3.2.6 (Huelsenbeck \& Ronquist, 2001),

155 respectively. JModelTest version 2.1.10 (Guindon \& Gascuel, 2003; Darriba et al., 2012) was

156 employed to select the most appropriate model of DNA evolution using the Akaike information

157 criterion (AIC). GTR $+\mathrm{I}+\mathrm{G}$ for $28 \mathrm{~S}$ rDNA and ITS1, and TIM3ef $+\mathrm{I}+\mathrm{G}$ for $18 \mathrm{~S}$ rDNA, were

158 selected as the best models of DNA evolution, using the following partition $18 \mathrm{~S}=1-446$, ITS1 $=$

$159447-745$ and $28 \mathrm{~S}=746-1533$. GTR model including the proportion of invariable sites and

160 gamma distribution were set for reconstruction of phylogenetic trees in RAxML and MrBayes. 
161 Support values for internal nodes were estimated using a bootstrap resampling procedure with 1621000 replicates (Felsenstein, 1985). The BI tree was constructed using four Monte Carlo Markov 163 chains (MCMC) running under 2000000 generations, with sampling tree topologies every 100 164 generations. The first $30 \%$ of the trees were discarded as "burn-in" according to the standard 165 deviation split frequency value $(<0.01)$. The posterior probabilities of the phylogeny and its 166 branches were determined for all trees left in the plateau phase with the best ML scores. 167

\section{Results}

Six Moroccan cyprinid fish species were examined for monogeneans: C. fritschii $(n=40), L$. ksibi $(n=15)$, L. lepineyi $(\mathrm{n}=113)$, L. rabatensis $(n=9)$, L. zayanensis $(\mathrm{n}=15)$ and $P$. maroccana $(n=3)$. In each species, the gills were infected with one or more species of Dactylogyrus. Four previously described species of Dactylogyrus were found (D. marocanus, D. integrated approach combining both morphological and molecular analysis, thereby making them available for phylogenetic and coevolutionary analysis.

Dactylogyrus marocanus El Gharbi, Birgi \& Lambert, 1994 (Fig. 2)

Type host: Carasobarbus fritschii (Günther, 1874) [syns. Barbus (Labeobarbus) fritschii, B. (L.) paytonii].

181 Type locality: Oum Er'Rabia Basin, Boulaouane; Morocco. 
184 Luciobarbus ksibi (Boulenger, 1905) [syn. Barbus (Barbus) ksibi], Luciobarbus nasus (Günther, 185 1874) [syn. Barbus (Barbus) nasus], Luciobarbus setivimensis (Valenciennes, 1842) [Barbus 186 (Barbus) setivimensis] (El Gharbi, Birgi \& Lambert, 1994). Identification of L. setivimensis as 187 host for D. marocanus is apparently erroneous (see Remarks for D. ksibii).

188 Other previously recorded localities: Oum Er'Rabia Basin (El Borj, Mechraa Ben Abbou); 189 Tensift Basin, Zate River (Ait Ourir); Ksob Basin (Essaouira); Sebou Basin, Ouargha River 190 (Ouazzane); Moulouya Basin (Mechraa Hammadi, Aklim); Morocco (El Gharbi, Birgi \& 191 Lambert, 1994).

192 Present hosts and localities: Carasobarbus fritschii (localities 1, 2, 6), Luciobarbus ksibi 193 (localities 1, 2), Luciobarbus zayanensis Doadrio, Casal-López \& Yahyaoui, 2016 (localities 3, 194 4), Pterocapoeta maroccana Günther, 1902 (locality 3).

195 Site on host: Gill lamellae.

196 Specimens deposited: Two vouchers (IPCAS M-750) and 2 hologenophores (IPCAS M-750) 197 from C. fritschii (Chbouka and Ksob River), 3 vouchers (IPCAS M-750) and 1 hologenophore 198 (IPCAS M-750) from L. ksibi (Chbouka River), 3 vouchers (MNHN HEL 1255, 1267) and 3 199 hologenophores (MNHN HEL1258, 1259; IPCAS M-750) from L. zayanensis (E1 Borj), and 6 200 vouchers (MNHN HEL1256, 1257) and 2 hologenophores (IPCAS M-750) from P. maroccana 201 (E1 Borj).

202

\section{Description}

204 Based on 10 specimens fixed in GAP. Body length 303 (263-348; $n=10)$; greatest width 80

$205(73-90 ; n=10)$ at level of ovary. One pair of anchors located dorsally: total length $44(41-50 ; n$ $206=10)$; length to notch $22(19-23 ; n=10)$; inner root length $18(15-20 ; n=10)$; outer root length 
$2072(1-3 ; n=10)$; point length $10(9-11 ; n=10)$. One pair of needles located near hooks of pair $\mathrm{V}$. 208 Dorsal bar straight, bone-shaped, with slightly enlarged lateral ends, $24(21-27 ; n=10)$ long. 209 Ventral bar reduced into thin rod-like structure, $13(12-15 ; n=10)$ long. Seven pairs of hooks; 210 each with delicate point, protruded thumb and shank inflated along proximal half; filamentous 211 hook (FH) loop extending to level of shank inflation. Hook lengths: pair I = $19(18-20 ; n=10)$; 212 pair II $=19(17-20 ; n=10)$; pair III = $22(20-25 ; n=10)$; pair IV = $23(21-26 ; n=10)$; pair $\mathrm{V}=$ $21318(16-19 ; n=10)$; pair VI =19 (16-24; $n=10)$; pair VII $18(15-23 ; n=10)$. MCO comprising 214 basally articulated copulatory tube and accessory piece; total straight length $44(38-57 ; n=10)$.

215 Copulatory tube J-shaped, with bulbous base and diameter sharply attenuated distally, 47 (41-61; $216 n=10$ ) long. Accessory piece rod-shaped, distally bifurcated to form two arms (one hook217 shaped). Vagina lightly sclerotized, $5(4-7 ; n=10)$ long.

218

\section{Molecular characterization}

220 The following DNA sequences were obtained for D. marocanus: partial 28S rDNA 787 bp long, 221 partial 18S rDNA 478 bp long, ITS1 region 483 bp long, and 5.8S rDNA 11 bp long. Eight 222 specimens from four host species (C. fritschii, L. ksibi, L. zayanensis and P. maroccana) 223 collected from different localities were sequenced, with no intraspecific genetic variability found

224 between different host species or between different localities. Accession numbers of $D$.

225 marocanus collected from different host species are included in Table 2. Pairwise genetic 226 distances between D. marocanus and other Moroccan Dactylogyrus spp. showed very high 227 molecular divergence (Table 3).

228

\section{Remarks}


230 231 232 233 234 235 236

Dactylogyrus marocanus was originally described from the gills of six species belonging to three cyprinid genera (Carasobarbus, Labeobarbus and Luciobarbus) inhabiting five large river basins in Morocco (El Gharbi, Birgi \& Lambert, 1994; see above). However, one of the host species recorded, L. setivimensis, was probably misidentified as the species only occurs naturally in coastal rivers in northeast Algeria (Soummam Basin) (Fricke, Eschmeyer \&Van de Laan, 2020). Dactylogyrus marocanus resembles several species belonging to the 'pseudanchoratus' speciesgroup defined in Paperna (1979), in that it has anchors with a markedly elongated inner root, short outer root and a proximally swollen shaft (an attachment point for the anchor filament). It most closely resembles Dactylogyrus longiphallus Paperna, 1973 from African cyprinids in that it possesses a J-shaped copulatory tube and a rod-shaped accessory piece distally bifurcated to form two arms that serve as a guide for the distal part of the copulatory tube. In addition, the MCO is markedly large in relation to the size of the haptoral structures in both species (compare with Plate XV, Figs. 1-11 in Paperna (1979)). However, D. marocanus is easily differentiated from other species belonging to the 'pseudanchoratus' species-group by the presence of the ventral bar. Dactylogyrus marocanus demonstrates a relatively low level of host specificity, having been recorded on eight host species of four genera from Morocco, including $L$. zayanensis and P. maroccana reported in our study. During the present survey, no morphological differences were found between specimens of this species collected from C. fritschii, L. ksibii, L. zayanensis and P. maroccana.

\section{Dactylogyrus ksibii El Gharbi, Birgi \& Lambert, 1994 (Figs. 3A, B)}

Type host: Luciobarbus ksibi (Boulenger, 1905) [syn. Barbus (Barbus) ksibi]

Type locality: Ksob Basin, Essaouira; Morocco. 
253 Other previously recorded hosts: Luciobarbus magniatlantis (Pellegrin, 1919) [syn. Barbus

254 (Barbus) magniatlantis], Luciobarbus setivimensis (Valenciennes, 1842) [syn. Barbus (Barbus)

255 setivimensis] (El Gharbi, Birgi \& Lambert, 1994). Identification of L. setivimensis as host for D.

$256 k s i b i i$ is apparently erroneous (see Remarks).

257 Other previously recorded localities: Oum Er'Rabia Basin (Borj, Bounual); Tensift Basin,

258 Ourika River (Ourika), Zate River (Ait Ourir); Mellah Basin (Khouribga); Bouregreg Basin,

259 Grou River (Moulay Bouazza), Boulahmayl River (Aguelmouss); Morocco (El Gharbi, Birgi \& 260 Lambert, 1994).

261 Present hosts and localities: Luciobarbus ksibi (Boulenger, 1905) (localities 1, 2), Luciobarbus 262 rabatensis Doadrio, Perea \& Yahyaoui, 2015 (locality 5).

263 Site on host: Gill lamellae.

264 Specimens deposited: Three vouchers (MNHN HEL1260) and one hologenophore (MNHN 265 HEL1262) from L. ksibi (Ksob River), one voucher (MNHN HEL1261) and one hologenophore 266 (MNHN HEL1263) from L. ksibi (Chbouka River), and two vouchers (IPCAS M-751) and two 267 hologenophores (MNHN HEL1264, IPCAS M-751) from L. rabatensis (Grou River).

268

269

270

271 272 273

274 pair V. Dorsal bar broadly V-shaped, with slightly narrowed median part, $32(29-35 ; n=20)$

275 long. Ventral bar cross-shaped, with five arms, $34(32-36 ; n=20)$ long, $27(24-30 ; n=20)$ wide. 
276 Seven pairs of hooks; each with delicate point, flattened thumb and shank inflated along 277 proximal two-thirds; FH loop extending to level of shank inflation. Hook lengths: pair I $=26$

$278(24-29 ; n=20)$; pair II = $25(23-26 ; n=20)$; pair III = $31(26-33 ; n=20)$; pair IV = 31 $(29-33$; $279 n=20)$; pair $\mathrm{V}=27(25-30 ; n=20)$; pair $\mathrm{VI}=29(27-31 ; n=20)$; pair VII $=28(26-30 ; n=$ 280 20). MCO comprising articulated copulatory tube and accessory piece; total straight length 30 $281(27-33 ; n=20)$. Copulatory tube a loose coil following sinuous path; $76(75-77 ; n=13)$ long. 282 Accessory piece proximally enclosing base of copulatory tube to form frill-belted capsule; 283 medial portion with three processes: primary process distally articulated to the capsule by lightly 284 sclerotized ligament; secondary process grooved, closely associated with wedge-shaped tertiary 285 process, serving as a guide for distal part of the tube; distal portion recurved, elongated, following medial part of the copulatory tube. Vagina a wavy tube, with enlarged funnel-shaped opening, $63(57-70 ; n=20)$ long.

288

289

\section{Molecular characterization}

290 291

292 293 294 295 296 297 298

The following DNA sequences were obtained for D. ksibii: partial 28S rDNA 792 bp long, partial 18S rDNA 478 bp long, ITS1 region 489 bp long, and 5.8S rDNA 11 bp long. Nine specimens of D. ksibii from three different river basins (Ksob, Oum Er'Rabia and Bouregreg) were sequenced (see Table 2 for accession numbers). Using molecular data, genetic variability was reported between specimens of D. ksibii parasitizing (i) L. ksibi collected from two different regions (Ksob River and Chbouka River), and (ii) different host species (L. ksibi and $L$. rabatensis). Pairwise distances calculated between D. ksibii and other Dactylogyrus species of Moroccan Luciobarbus are shown in Table 3. 


\section{Remarks}

300 El Gharbi, Birgi \& Lambert (1994) described D. ksibii from specimens collected on the gills of

301 L. ksibi from the Ksob and Oum Er'Rabia Rivers, L. magniatlantis from the Tensift River

302 (Tensift Basin) and L. setivimensis from the Boulahmayl (Bouregreg Basin) and Mellah (Mellah

303 Basin) Rivers. However, host identification of the latter host species is probably erroneous (for

304 the reason suggested above), with L. rabatensis apparently captured instead of L. setivimensis in 305 the Boulahmayl River (Bouregreg Basin). All cyprinid specimens collected from the Bouregreg

306 Basin during the present survey were identified as L. rabatensis (J. Vukic, pers. comm.). The

307 Bouregreg Basin represents the current distribution area of this endemic Moroccan species

308 (Casal-López et al., 2015). In the original description of D. ksibii, El Gharbi, Birgi \& Lambert

309 (1994) showed four iconotypes for the MCO, without indicating which corresponded to the

310 specimens of $D$. ksibii found on the type host species and locality (i.e. L. ksibi, Ksob River). In

311 addition, these authors reported morphometric variation in the haptoral sclerites among

312 specimens of D. ksibii parasitizing different host species and occurring in different localities.

313 Rahmouni et al. (2017) suggested that these morphological differences in the haptoral sclerites

314 could indicate that $D$. ksibii represented a complex of several morphologically similar species. In

315 the present study, specimens morphologically identified as $D$. ksibii were found on the gills of $L$.

$316 k s i b i$ (= type host) and L. rabatensis. Subsequent DNA analysis revealed that the specimens of

317 D. ksibii consisted of three genotypes, one found on L. ksibi collected in the Ksob River, one on

318 the same host species but from the Chbouka River and one on L. rabatensis from the Grou River.

319 A posteriori analysis of the specimens associated with the three genotypes revealed no

320 morphological basis for splitting D. ksibii into two or three species (see Figs. 3A, B). Given that 
321 the level of morphological variation observed corresponds more to intraspecific variation, no

322 new Dactylogyrus species are named at this time.

323 Dactylogyrus ksibii belongs to the group of congeners having a cross-shaped ventral bar (=

324 'carpathicus' type; El Gharbi, Birgi \& Lambert, 1994). The MCO of D. ksibii most closely

325 resembles that of D. scorpius Rahmouni, Řehulková \& Šimková 2017, D. benhoussai Rahmouni,

326 Řehulková \& Šimková 2017 and D. varius Rahmouni, Řehulková \& Šimková 2017, all three

327 parasitizing species of Moroccan Luciobarbus and morphologically belonging to the 'scorpius'

328 group (Rahmouni et al., 2017). Dactylogyrus ksibii differs from these three species by possessing

329 a longer copulatory tube (76 vs 45 in D. scorpius; 76 vs 67 in D. benhoussai; 76 vs 65 in D.

330 varius) and by details in the structure of the accessory piece. The accessory piece of $D$. ksibii is

331 characterized by a medial part with a primary process closely associated with the secondary

332 process (medial part with primary and secondary processes well defined/separated in $D$.

333 scorpius, D. benhoussai and D. varius) and by a comparatively robust distal part (distal part

334 smaller in D. scorpius, D. benhoussai and D. varius).

335

336 Dactylogyrus borjensis El Gharbi, Birgi \& Lambert, 1994 (Fig. 4)

337 Type host: Luciobarbus zayanensis Doadrio, Casal-López \& Yahyaoui, 2016, previously

338 referred to as Luciobarbus nasus [syn. Barbus (Barbus) nasus] (see Remarks).

339 Type locality: Oum Er'Rabia Basin, El Borj; Morocco.

340 Other previously recorded hosts: Luciobarbus magniatlantis (Pellegrin, 1919), previously

341 referred to as L. nasus [syn. B. (B.) nasus] (El Gharbi, Birgi \& Lambert, 1994) (see Remarks).

342 Other previously recorded locality: Tensift Basin, Zate River (Ait Ourir); Morocco (El Gharbi,

343 Birgi \& Lambert, 1994). 
344 Present host and localities: Luciobarbus zayanensis Doadrio, Casal-López \& Yahyaoui, 2016

345 (localities 3, 4).

346 Site on host: Gill lamellae.

347 Specimens deposited: Three vouchers (MNHN HEL1265-1267) and two hologenophores

348 (MNHN HEL1268, 1269) from L. zayanensis (El Borj), and one voucher (IPCAS M-752) from

349 L. zayanensis (Dar Oulad Zidouh).

350

351 Description

352 Based on 24 specimens fixed in GAP. Body length $624(540-683 ; n=24)$; greatest width 123

$353(100-130 ; n=24)$ at level of ovary. One pair of anchors located dorsally: total length 47 (44-48;

$354 n=24)$; length to notch $41(40-42 ; n=24)$; inner root $17(15-19 ; n=24)$ long; outer root $5(4-6$;

$355 n=24)$ long; shaft curved, slightly swollen medially; point $12(11-13 ; n=24)$ long. One pair of

356 needles located near hooks of pair V. Dorsal bar broadly V-shaped, with slightly rounded

357 extremities, $36(34-37 ; n=24)$ long. Ventral bar cross-shaped, with five arms, $36(34-38 ; n=$

358 24) long, $28(26-31 ; n=24)$ wide. Seven pairs of hooks; each with delicate point, flattened

359 thumb and shank inflated along proximal four-quarters; FH loop extending to level of shank

360 inflation. Hook lengths: pair I = $25(23-26 ; n=24)$; pair II = 26 (25-28; $n=24)$; pair III = 31

$361 \quad(29-33 ; n=24)$; pair IV $=31(29-34 ; n=24)$; pair $\mathrm{V}=25(23-27 ; n=24)$; pair VI = $27(26-30$;

$362 n=24)$; pair VII $=28(26-30 ; n=24)$. MCO complex, comprising articulated copulatory tube

363 and accessory piece; total straight length $40(36-42 ; n=24)$. Copulatory tube a loose coil

364 following sinuous path; $111(107-120 ; n=12)$ long. Accessory piece proximally enclosing base

365 of copulatory tube to form frill-belted capsule; distal portion recurved, elongated, following

366 medial part of copulatory tube; medial portion with three processes: primary process distally 
367 articulated to the capsule by lightly sclerotized ligaments; secondary process apically expanded 368 into a wing like flap, closely associated with tertiary process serving as a guide for distal

369 termination of the tube. Vagina a lightly sclerotized meandering tube, with disc-shaped opening, $37092(88-98 ; n=24)$ long.

371

372 Molecular characterization

373 The following DNA sequences were obtained for D. borjensis: partial 28S rDNA 792 bp long, 374 partial 18S rDNA 478 bp long, ITS1 region 489 bp long, and 5.8S rDNA 11 bp long. Three 375 specimens of $D$. borjensis from the Oum Er'Rabia River were sequenced, and no intraspecific 376 variation between the specimens of this species was noted. Pairwise distances between $D$. 377 borjensis and the other Dactylogyrus species from Moroccan Luciobarbus are shown in Table 3. 378

379 Remarks

380 The type specimens of $D$. borjensis were not available (see Rahmouni et al., 2017). Based on the 381 morphology of the haptoral and copulatory sclerites showed by El Gharbi, Birgi \& Lambert 382 (1994), we consider our samples to be conspecific with this species. The original description is 383 adequate except that these authors depicted the accessory piece of the MCO with the largest 384 (secondary) medial process expanded into a tube through which the distal (recurved) part passes. 385 As in other species of Dactylogyrus belonging to the "scorpius" group, the accessory piece is 386 somewhat variable in this species, with the distal part bending inward to the right or left side of 387 the medial part. This variability is likely a result of the compression used during preparation of 388 individual worms for mounting. It appears likely that El Gharbi, Birgi \& Lambert (1994) 389 misinterpreted the distal part of the accessory piece as incorporated into the tubular part of the 
390 largest medial process, instead of lying under or above this part. In the present specimens of $D$. 391 borjensis, the distal part of the accessory piece is not associated with any processes of the medial 392 part. The largest process of the accessory piece is terminally extended to form wing like flap 393 usually rolled in the shape of a sleeve, which serves as a guide for the distal part of the 394 copulatory tube, and not for the distal part of the accessory piece as it is depicted in the original 395 description of $D$. borjensis.

Dactylogyrus borjensis is most similar to D. falsiphallus Rahmouni, Řehulková \& Šimková, 2017, described on the gills of L. maghrebensis from the Lahdar and Sebou rivers (Sebou Basin) 398 (Rahmouni et al., 2017), in the general morphology of the haptoral sclerites and MCO. It differs from $D$. falsiphallus by having relatively robust and evenly sclerotized distal part of the accessory piece (distal part reduced in its sclerotization into a long spike in D. falsiphallus). In addition, the MCO is measurably smaller in D. falsiphallus.

El Gharbi, Birgi \& Lambert (1994) listed L. nasus [syn. B. (B.) nasus] as the type host for this 403 species. According to Doadrio, Casal-López \& Perea (2016) the rheophilic Luciobarbus populations traditionally assigned to L. nasus (Günther, 1874) and L. magniatlantis (Pellegrin, 1919) comprise three species, each endemic for different basins in Morocco. Luciobarbus nasus is restricted to the Ksob Basin, L. magniatlantis to the Tensift Basin, and the recently described

407 L. zayanensis to the Oum Er'Rabia Basin. Since the last basin represents the type locality for $D$. 408 borjensis, we consider L. zayanensis as the type host of this species. The additional host record 409 of D. borjensis on a population of Luciobarbus species previously referred to L. nasus from 410 Tensift Basin (El Gharbi, Birgi \& Lambert, 1994) should be attributed to L. magniatlantis.

\section{Dactylogyrus draaensis El Gharbi, Birgi \& Lambert, 1994 (Fig. 5)}


413 Type host: Luciobarbus pallaryi (Pellegrin, 1919) [syn. Barbus (Barbus) pallaryi].

414 Type locality: Draa Basin, Dadès River, Ait Oudinar; Morocco.

415 Other previously recorded locality: Draa Basin, Tidili River, Iouine River; Morocco (E1

416 Gharbi, Birgi \& Lambert, 1994).

417 Present host and locality: Luciobarbus lepineyi (Pellegrin, 1939) (locality 7).

418 Site on host: Gill lamellae.

419 Specimens deposited: Two vouchers (MNHN HEL1351, 1352) from L. lepiney (Zouala Oasis).

420

421 Description

422 Based on 30 specimens fixed in GAP. Body length $790(645-901 ; n=16)$; greatest width 120

$423(110-125 ; n=30)$ at level of ovary. One pair of anchors located dorsally: total length $51(48-55$;

$424 n=30)$; length to notch $39(36-42 ; n=30)$; inner root length $19(17-21 ; n=30)$; outer root

425 length $5(3-6 ; n=30)$; point length $12(11-14 ; n=30)$. One pair of needles located near hooks of

426 pair V. Dorsal bar broadly V-shaped, $41(34-45 ; n=30)$ long. Ventral bar cross-shaped, with

427 five arms, $51(37-56 ; n=30)$ long, $36(27-45 ; n=30)$ wide. Seven pairs of hooks; each with

428 delicate point, flattened thumb and shank inflated along proximal two-thirds; FH loop extending

429 to level of shank inflation. Hook lengths: pair I $=29(25-35 ; n=27)$; pair II $=29(25-32 ; n=$

430 29); pair III = $31(29-35 ; n=25)$; pair IV = $31(24-36 ; n=29)$; pair $\mathrm{V}=28(24-33 ; n=29)$; pair

$431 \mathrm{VI}=31(27-38 ; n=28)$; pair VII $=31(28-36 ; n=25)$. MCO complex, comprising articulated

432 copulatory tube and accessory piece; total straight length $43(40-52 ; n=30)$. Copulatory tube

433 sinuous, $116(113-120 ; n=25)$ long. Accessory piece proximally enclosing base of copulatory

434 tube; medial portion with two auricle-like processes; distal portion recurved, following medial 
435 part of the copulatory tube. Vagina a lightly sclerotized meandering tube, $54(47-60 ; n=30)$

436 long.

437

438 Molecular characterization

439 The following DNA sequences were obtained for D. draaensis: partial 28S rDNA 792 bp long, 440 partial 18S rDNA 478 bp long, ITS1 region 489 bp long, and 5.8S rDNA 11 bp long. Three 441 specimens of $D$. draaensis from the Zouala Oasis were sequenced, with no intraspecific

442 variability between specimens of this species noted. Pairwise distances between D. draaensis and 443 the other Dactylogyrus species of Moroccan Luciobarbus are shown in Table 3.

444

445 Remarks

446 Dactylogyrus draaensis was originally described from the gills of L. pallaryi from two rivers in 447 the Draa Basin (El Gharbi, Birgi \& Lambert, 1994). The species is characterized by possessing a 448 sinuous copulatory tube with the distal part supported by two auricle-like processes rising from 449 the accessory piece. During the present survey, specimens provisionally identified as $D$. 450 draaensis were collected from L. lepineyi in the Zouala Oasis. The drawings provided by El 451 Gharbi, Birgi \& Lambert (1994) were unclear regarding the morphology of the medial part of the 452 accessory piece, hence we cannot state with certainty that our specimens are conspecific with 453 those of $D$. draaensis from the Draa Basin. Assignment of a new species name to our specimens 454 is not made at this time and will depend on re-collection of $D$. draaensis from the type host in the 455 type locality for comparison with our specimens.

456 


\section{Phylogenetic reconstruction}

458 A concatenated sequence alignment (partial 28S, 18S rDNA and ITS1 combined) was used to 459 construct a phylogenetic tree including 24 species, the alignment comprising 1458 aligned 460 positions. Both ML and BI phylogenetic analyses yielded similar tree topologies. The BI tree is 461 presented in Fig. 6, with bootstrap support values for ML and posterior probabilities for BI.

462 The phylogenetic reconstruction divided Dactylogyrus spp. parasitizing Moroccan cyprinids into 463 three lineages. The first well-supported clade includes three species of Dactylogyrus (D.

464 kulindrii, D. volutus, and D. zatensis) from Northwest African C. fritschii (Torinae) (Table 4). 465 These species all have 'varicorhini' type of the anchors and bars: the anchors possess shaft 466 turned into a point with a sharp-stepped narrowing from the inner side of the anchor; dorsal bar 467 is saddle-shaped with posterior groove, usually giving the impression of butterfly wings; and 468 ventral bar is V- or omega-shaped (El Gharbi, Renaud \& Lambert, 1992; Pugachev et al., 2009). 469 A sister relationship between D. volutus and D. kulindrii is also supported by morphological 470 similarities in their MCOs, i.e. the copulatory tube is relatively wide in diameter and a simple 471 accessory piece possesses two projections guiding the distal portion of the copulatory tube. The 472 second clade, with several subclades, comprises species of Dactylogyrus collected from 473 European and Moroccan species of Barbus and Luciobarbus (Table 4). Dactylogyrus 474 andalousiensis El Gharbi, Renaud \& Lambert, 1992 from Iberian Luciobarbus sclateri (Günther, 475 1868) (Portugal) was sister to a well-supported clade formed by nine species of Dactylogyrus 476 parasitizing Moroccan Luciobarbus, all of which were characterized by i) a cross-shaped ventral

477 bar with five extremities (= ‘carpathicus' or 'barbus' type; see Pugachev et al., 2009), ii) an 478 MCO possessing an accessory piece with the distal portion directed backwards along the circle 479 of the curved copulatory tube (= 'chondrostomi' type; see Pugachev et al., 2009), a complex 
480 medial portion formed into ridge-shaped processes supporting the distal part of the copulatory

481 tube and capsule-like proximal portion (= 'scorpius' subtype; Rahmouni et al., 2017). The basal

482 position of D. draaensis in relation to the other Dactylogyrus spp. from Moroccan Luciobarbus

483 was moderately supported by PP resulting from BI analysis and moderately/weakly supported by

484 BP resulting from ML analysis. Four Dactylogyrus species formed the well-supported clade

485 including two weakly supported assemblages: the first one represented by $D$. benhoussai

486 and $D$. varius and the second one represented by D. scorpius and three genotypes of D. ksibii.

487 All four Dactylogyrus species are morphologically very similar, both in the haptoral structures

488 and the MCOs. Finally, D. marocanus formed a separated lineage supported by differing

489 morphology.

490

491 Discussion

492 Since the anatomical details of dactylogyrids are generally poorly known, discrimination

493 between species of Dactylogyrus relies chiefly on the morphometric characteristics of sclerotized

494 structures of the haptor and reproductive organs. In recent years, however, molecular

495 phylogenetic analysis has revealed hidden genetic variation and/or cryptic species within this

496 genus. Rahmouni et al. (2017) reported two cryptic species of Dactylogyrus (D. benhoussai and

497 D. varius) on two species of Moroccan Luciobarbus (L. yahyaouii and L. maghrebensis,

498 respectively), while Benovics et al. (2018) revealed potential cryptic species complexes within

499 three species of Dactylogyrus (Dactylogyrus rutili Gläser, 1965, Dactylogyrus dyki Ergens \&

500 Lucký, 1959 and Dactylogyrus ergensi Molnár, 1964) parasitizing Balkan cyprinids. As different

501 ribosomal DNA molecular markers show differing rates of evolution, they are appropriate for

502 evaluating genetic divergence at different levels (Huelsenbeck \& Ronquist, 2001). In the present 
503 study, we applied genetic markers widely used for monogeneans, i.e. 18S rDNA, 28S rDNA and 504 the ITS1 region (Cunningham, 1997; Meinilä et al. 2002; Ziętara \& Lumme, 2002). Molecular

505 characterization of Dactylogyrus species in our study showed that specimens identified 506 morphologically as $D$. ksibii, collected from the gills of two different hosts ( $L$. ksibi and $L$. 507 rabatensis) and geographically distant basins, exhibited a low level of intraspecific variability $508 \quad(0.8 \%$ for the combined $18 \mathrm{~S}$ rDNA and ITS1 sequences). Molecular divergence observed 509 between specimens of $D$. ksibii (i.e. those parasitizing $L$. ksibi from Ksob River, L. ksibi from 510 Chbouka River, and L. rabatensis from Grou River) may be explained by the large geographical 511 distances between parasites and hosts precluding gene flow between isolated populations. Our 512 findings indicate that specimens of D. ksibii reported by El Gharbi, Birgi \& Lambert (1994) from 513 Luciobarbus species inhabiting various river basins in Morocco need serious reinvestigation in 514 the future using morphological and molecular data.

515 Besides providing crucial taxonomic information on species, the sclerotized structures of the 516 haptor and reproductive organs are of particular interest in evolutionary studies focused on the 517 link between morphological and molecular interspecific similarities of Dactylogyrus spp. (e.g. 518 Benovics, Kičinjaová \& Šimková, 2017; Benovics et al., 2018). In addition, as the morphology 519 of the attachment organ is usually viewed as the result of adaptive processes to the host 520 microenvironment (e.g. Kearn, 1994; Vignon \& Sasal, 2010), the morphological characteristics 521 of the haptor may have the potential to reflect the phylogeny and historical biogeographical 522 routes of their hosts (e.g. Šimková et al., 2006). On the basis of morphological resemblance, 523 many Dactylogyrus species can be grouped into morphological types, often derived from a single 524 structure (Pugachev et al., 2009). Some of these groups may be considered as phylogenetic units, 525 members of one unit often parasitizing closely related hosts. However, it is relatively difficult to 
526 determine to what extent morphological features reflect a phylogenetic signal unless adaptive

527 forces associated with the possibility of host switching can be excluded.

528 Based on the shape of the ventral bar, species of Dactylogyrus parasitizing Luciobarbus spp. are

529 grouped into four morphological types, i.e. those with a rod-shaped, omega-shaped, inverted T-

530 shaped or cross-shaped ventral bar (see Pugachev et al., 2009). All Moroccan species of

531 Dactylogyrus that are host-specific to Luciobarbus spp. belong to the group with a cross-shaped

532 ventral bar, where the anterior arm is widely bifurcated and the posterior arm is more or less split

533 (= five radial type; 'carpathicus' or 'barbus' type in El Gharbi, Birgi \& Lambert (1994) and

534 Pugachev et al. (2009), respectively). Dactylogyrus spp. with this type of ventral bar have also

535 been recorded on Luciobarbus spp. inhabiting the Balkan Peninsula (Řehulková, Benovics \&

536 Šimková, 2020) and the region around the Caspian Sea (Pugachev et al., 2009), and on Aulopyge

537 huegelii Benovics, Kičinjaová \& Šimková, 2017 in the Balkans (Benovics, Kičinjaová \&

538 Šimková, 2017). The majority of Dactylogyrus species (except D. andalousiensis and

539 Dactylogyrus linstowoides) reported on Luciobarbus spp. on the Iberian Peninsula have V- or

540 omega-shaped ventral bars. Inasmuch as the haptor has to be evolutionary adapted as far as

541 possible to the host microenvironment (e.g. Kearn, 1968; Šimková et al., 2001), the same

542 morphological type of haptor in Moroccan and Balkan-Caspian Dactylogyrus spp. may suggest

543 that Luciobarbus spp. inhabiting these regions share a common ancestor. This assumption is also

544 supported by Tsigenopoulos et al. (2003) and Yang et al. (2015), who showed that most

545 Luciobarbus spp. from Northwest Africa are more closely related to Luciobarbus spp., from the

546 Middle East than to those from the Iberian Peninsula. In addition, on the basis of phylogenetic

547 reconstruction, Šimková et al. (2017) demonstrated that species of Dactylogyrus parasitizing

548 northwest African Luciobarus have a European/west Asian origin. When looking at MCO 
549 morphology, the 'Moroccan' and 'Balkan-Caspian' species of Dactylogyrus with a cross-shaped

550 ventral bar are characterized by different types of MCO, i.e. the 'chondrostomi' and 'kulwieci'

551 types, respectively (Pugachev et al., 2009). However, the 'chondrostomi' group, characterized by

552 an accessory piece with the distal portion directed backwards along the circle of the curved

553 copulatory tube, is one of the most specious groups within the Palaearctic species of

554 Dactylogyrus exhibiting different types of ventral bar (Pugachev et al., 2009). On the basis of

555 detailed morphology of the accessory piece, it would appear that Moroccan species of

556 Dactylogyrus form another subgroup within the 'chondrostomi' group, named by Rahmouni et

557 al. (2017) as the 'scorpius' subgroup. This subgroup is characterized by an accessory piece with

558 a complex medial portion formed into ridge-shaped processes supporting the distal part of the

559 copulatory tube and a relatively massive capsule-like proximal portion. It would be interesting to

560 further investigate the degree of relatedness between Moroccan and other Dactylogyrus spp. with

561 the 'chondrostomi' type of $\mathrm{MCO}$, with the intention of answering the question of whether the

562 similarity between MCOs is a result of homoplasy or shows a phylogenetic signal.

563 Concerning host specificity, D. marocanus exhibits an unusually broad host range that includes

564 phylogenetically distant host species. Our records of D. marocanus on the gills of L. zayanensis

565 and $P$. maroccana increase the range of available host species such that the host range now

566 includes eight species of four cyprinid genera representing two phylogenetic lineages, i.e. the

567 Torinae, including Carasobarbus, Labeobarbus and Pterocapoeta, and the Barbinae, including

568 Luciobarbus. El Gharbi, Birgi \& Lambert (1994) suggested that C. fritschii [syn. Labeobarbus

569 fritschii] represents the original host of D. marocanus; however, Šimková et al. (2017) showed

570 that D. marocanus is closely related to Dactylogyrus spp. parasitizing West African species

571 assigned to Labeo, which suggests a host-switch from African labeonins to C. fritschii and the 
572 other reported northwest African cyprinid hosts. In terms of morphology, D. marocanus is the

573 only Moroccan Dactylogyrus species belonging to the 'pseudanchoratus' group (El Gharbi, Birgi

574 \& Lambert, 1994), which includes Dactylogyrus spp. reported on cyprinids (mostly species of

575 Labeo) from the wider equatorial region in Africa (Paperna, 1979) and, interestingly,

576 Dactylogyrus spp. parasitizing Garra rufa (Labeoninae) in Iran (Gussev, Jalali \& Molnár, 1993;

577 Pugachev et al., 2009). The molecular phylogeny of labeonins provided by Tang, Getahun \& Liu 578 (2009) showed that the Asian G. rufa and African Garra spp. formed sister groups, and that this 579 Afro-Asian clade was nested within a larger clade containing all other Asian Garra spp. In 580 addition, their study supports an East Asian origin of labeonins, and into-Africa dispersal events 581 for the African species of Garra and Labeo. If the phylogeny of highly host-specific parasites 582 follows the phylogeny and historical biogeography of their hosts, it would be interesting to 583 analyze the phylogenetic relationship between Dactylogyrus spp. parasitizing G. rufa and those 584 of the 'pseudanchoratus' group (including D. marocanus) parasitizing African labeonins. The 585 close relationship between these Dactylogyrus spp., supported by both morphological and 586 molecular data, could point to their common Asian origin.

587 In accordance with the study of Šimková et al. (2017) we showed that Dactylogyrus species 588 parasitizing northwest African cyprinid fishes belong to three evolutionary lineages.

589 Dactylogyrus spp. from Moroccan species of Luciobarbus (Barbinae) represent the largest 590 (monophyletic) group in number of species. High similarity in morphology of the sclerotized

591 structures in these parasites, together with high host specificity, could suggest rapid

592 diversification following the geographical separation and diversification of Luciobarbus spp. The 593 basal position of D. andalousiensis parasitizing Iberian L. sclateri in relation to the monophyletic 594 group including Dactylogyrus spp. parasitizing Moroccan Luciobarbus spp. (Barbinae) strongly 
595 supports a European origin for this group of parasites, as previously shown by Šimková et al.

596 (2017). Dactylogyrus spp. parasitizing fishes of Moroccan Torinae (species of Carasobarbus and

597 Labeobarbus) form the second largest group characterized by the 'varicorhini' morphological

598 type of sclerotized structures (El Gharbi, Birgi \& Lambert, 1994), probably originating from

599 Asian cyprinids (Šimková et al., 2017). Mapping the evolutionary history of D. marocanus is

600 difficult due to its low level of host specificity; however, morphological and molecular data

601 suggest an affinity of this species to Dactylogyrus spp. parasitizing African labeonins (Šimková

602 et al., 2017). The phylogenetic position of Dactylogyrus guirensis El Gharbi, Birgi et Lambert,

603 1994, the only Moroccan species of the 'guirensis' morphological type (El Gharbi, Birgi \&

604 Lambert, 1994), remains unresolved as no molecular data are available for this species at this 605 time.

606

\section{Conclusion}

608 The present study represents one more step towards the understanding of morphological and

609 phylogenetic relationships among species of Dactylogyrus (i.e. at the levels of inter- and

610 intraspecific variability) parasitizing cyprinoid fishes. Our phylogenetic reconstruction of

611 Dactylogyrus species from Moroccan cyprinids supports that the morphological characters

612 formerly proposed by El Gharbi, Birgi \& Lambert (1994) and further developed by Rahmouni et

613 al. (2017) to group species of Dactylogyrus are relevant. Our results also show that a detailed

614 morphological analysis of closely related monogeneans is an essential part of integrative

615 taxonomy, not only for accurate delimitation of species (or justifying of cryptic species) but also

616 for searching the link between morphology and molecules in phylogenetic and cophylogenetic

617 studies. This is especially true for species of Dactylogyrus undergoing probable rapid speciation 
618 without discernible morphological differentiation, such as some of those parasitizing Moroccan 619 cyprinids.

620

\section{Acknowledgements}

622 We are grateful to Jasna Vukić from Faculty of Science, Charles University, Prague, for fish 623 collection, determination and valuable discussion concerning current taxonomy of Luciobarbus 624 spp. Thanks are due to Mária Lujza Červenka Kičinja and Tomáš Pakosta for their help with the 625 fish examination, parasite collection and fixation. We are also grateful to Delane Kritsky and two 626 anonymous reviewers whose comments greatly improved the manuscript. We thank Professor 627 Abdelaziz Benhoussa from Mohamed V University of Rabat for the help in the fish collection. 628 We kindly thank Kevin Roche for the English revision of the final draft.

629

630

\section{References}

Benovics M, Desdevises Y, Vukić J, Šanda R, Šimková A. 2018. The phylogenetic relationships and species richness of host-specific Dactylogyrus parasites shaped by the 633 biogeography of Balkan cyprinids. Scientific Reports 8:13006.

Benovics M, Kičinjaová ML, Šimková A. 2017. The phylogenetic position of the enigmatic Balkan Aulopyge huegelii (Teleostei: Cyprinidae) from the perspective of host-specific \& Vectors 10:547.

Brahimi A, Libois R, Henrard A, Freyhof J. 2018. Luciobarbus lanigarensis and L. numidiensis, two new species of barbels from the Mediterranean Sea basin in North Africa

640 (Teleostei: Cyprinidae). Zootaxa 4433:542-560. 
641 Casal-López M, Perea S, Yahyaoui A, Doadrio I. 2015. Taxonomic review of the genus

642 Luciobarbus Heckel, 1843 (Actinopterygii, Cyprinidae) from northwestern Morocco with the

643 description of three new species. Graellsia 71:e027.

644 Cunningham CO. 1997. Species variation within the internal transcribed spacer (ITS) region of

645 Gyrodactylus (Monogenea: Gyrodactylidae) ribosomal RNA genes. Journal of Parasitology

646 83:215-219.

647 Darriba D, Taboala GL, Doallo R, Posada D. 2012. JModelTest2: more models, new

648 heuristics and parallel computing. Nature Methods 9:772.

649 Doadrio I, Casal-López M, Perea S. 2016. Taxonomic remarks on Barbus moulouyensis

650 Pellegrin, 1924 (Actinopterygii, Cyprinidae) with the description of a new species of

651 Luciobarbus Heckel, 1843 from Morocco. Graellsia 72:e054.

652 Doadrio I, Casal-López M, Perea S, Yahyaoui A. 2016. Taxonomy of rheophilic Luciobarbus

653 Heckel, 1842 (Actinopterygii, Cyprinidae) from Morocco. Graellsia 72:e039.

654 El Gharbi S, Birgi E, Lambert A. 1994. Monogènes Dactylogyridae parasites de Cyprinidae du 655 genre Barbus d'Afrique du Nord. Systematic Parasitology 27:45-70.

656 El Gharbi S, Renaud F, Lambert A. 1992. Dactylogyrids (Platyhelminthes: Monogenea) of 657 Barbus spp. (Teleostei: Cyrpinidae) from the Iberian Peninsula. Research and Reviews in 658 Parasitology 52:103-116.

659 Felsenstein J. 1985. Confidence limits on phylogenies: an approach using the bootstrap.

660 Evolution 39:91-783.

661 Fricke R, Eschmeyer WN, Van der Laan R. 2020. Eschmeyer's Catalog of Fishes: genera, 662 species, references. Available at 
663 http://researcharchive.calacademy.org/research/ichthyology/catalog/fishcatmain.asp (accessed 10

664 March 2020).

665 Gibson DI, Timofeeva TA, Gerasev PI. 1996. A catalogue of the nominal species of the

666 monogenean genus Dactylogyrus Diesing, 1850 and their host genera. Systematic Parasitology

$66735: 3-48$.

668 Guindon S, Gascuel O. 2003. A simple, fast and accurate algorithm to estimate large

669 phylogenies by maximum likelihood. Systematic Biology 27:1759-1767.

670 Gussev AV, Jalali B, Molnár K. 1993. New and known species of Dactylogyrus Diesing, 1850

671 (Monogenea, Dactylogyridae) from Iranian freshwater cyprinid fishes. Systematic Parasitology

$672 \quad 25: 221-228$.

673 Hall TA. 1999. BioEdit: a user-friendly biological sequence alignment editor and analysis

674 program for windows 95/98/NT. Nucleic Acids Symposium Series 41:8-95.

675 Hassouna N, Michot B, Bachellerie JP. 1984. The complete nucleotide sequence of mouse 28S

676 rRNA gene. Implications for the process of size increase of the large subunit rRNA in higher

677 eukaryotes. Nucleic Acids Research 35:63-83.

678 Huelsenbeck JP, Ronquist F. 2001. MRBAYES: Bayesian inference of phylogenetic trees.

679 Bioinformatics 17:754-755.

680 Kearn GC. 1968. The development of the adhesive organs of some diplectanid, tetraonchid and 681 dactylogyrid gill parasites (Monogenea). Parasitology 58:63-149.

682 Kearn GC. 1994. Evolutionary expansion of the Monogenea. International Journal of

683 Parasitology 24:1227-71.

684 Malmberg G. 1957. On the occurrence of Gyrodactylus on Swedish fishes. Skrifter Utgivna av

685 Södra Sveriges Fiskeriförening, Arsskrift 1956:19-76 [in Swedish]. 
686 Meinilä M, Kuusela J, Ziętara M, Lumme J. 2002. Primers for amplifying $\sim 820$ bp of highly

687 polymorphic mitochondrial COI gene of Gyrodactylus salaris. Hereditas 137:72-74.

688 Mizelle JD. 1936. New species trematodes from the gills of Illinois fishes. American Midland

689 Naturalist 17:785-806.

690 Paperna I. 1979. Monogenea of inland water fish in Africa. Annales du Musée Royal d'Afrique

691 Centrale, Sciences Zoologiques 26:1-131.

692 Pugachev ON, Gerasev PI, Gussev AV, Ergens R, Khotenowsky I. 2009. Guide to

693 Monogenoidea of freshwater fish of Palaearctic and Amur regions. Milan: Ledizione-Ledi

694 Publishing.

695 Rahmouni I, Řehulková E, Pariselle A, Berrada Rkhami O, Šimková A. 2017. Four new

696 species of Dactylogyrus (Monogenea: Dactylogyridae) parasitizing the gills of northern

697 Moroccan Luciobarbus (Cyprinidae): morphological and molecular characterization.

698 Systematic Parasitology 94:575-591.

699 Řehulková E. 2018. Ectoparasitic helminths (Monogenea). In: Scholz T, Vanhove MPM, Smit

700 N, Jayasundera, Z., Gelnar, M., eds. A guide to the parasites of African freshwater fishes. $A B C$

701 Taxa 18:89-98.

702 Řehulková E, Benovics M, Šimková A. 2020. Uncovering diversity of monogeneans

703 (Platyhelminthes) on endemic cypriniform fishes of the Balkan Peninsula: new species of

704 Dactylogyrus and comments on their phylogeny and host-parasite associations in biogeographic

705 context. Parasite 27: 66.

706 Stamatakis A. 2014. Raxml version 8: a tool for phylogenetic analysis and post-analysis of large

707 phylogenies. Bioinformatics 30:1312-1313. 
708 Šimková A, Benovics M, Rahmouni I, Vukić J. 2017. Host-specific Dactylogyrus parasites

709 revealing new insights on the historical biogeography of Northwest African and Iberian cyprinid

710 fish. Parasites \& Vectors 10:589.

711 Šimková A, Plaisance L, Matějusová I, Morand S, Verneau O. 2003. Phylogenetic

712 relationships of the Dactylogyridae Bychowsky, 1933 (Monogenea: Dactylogyridea): The need

713 for the systematic revision of the Ancyrocephalinae Bychowsky, 1937. Systematic Parasitology

$714 \quad 54: 1-11$.

715 Šimková A, Sasal P, Kadlec D, Gelnar M. 2001. Water temperature influencing dactylogyrid 716 species communities in roach, Rutilus rutilus, in the Czech Republic. Journal of Helminthology 717 75:373-383.

718 Šimková A, Verneau O, Gelnar M, Morand S. 2006. Specificity and specialization of 719 congeneric monogeneans parasitizing cyprinid fish. Evolution 60:1023-1037.

720 Talavera G, Castresana J. 2007. Improvement of phylogenies after removing divergent and 721 ambiguously aligned blocks from protein sequence alignments. Systematic Biology 56:564-577.

722 Tamura K, Stecher G, Peterson D, Filipiski A, Kumar S. 2013. MEGA6: Molecular 723 evolutionary genetics analysis version 6.0. Molecular Biology and Evolution 30:2725-2729.

724 Tang QY, Getahun A, Liu HZ. 2009. Multiple in-to-Africa dispersals of labeonin fishes 725 (Teleostei: Cyprinidae) revealed by molecular phylogenetic analysis. Hydrobiologia 632:261726271.

727 Thompson JD, Higgins DG, Gibson TJ. 1994. CLUSTAL W: Improving the sensitivity of 728 progressive multiple sequence alignment through sequence weighting, position-specific gap 729 penalties and weight matrix choice. Nucleic Acids Research 22:4673-4680. 
730 Tsigenopoulos CS, Hellemans B, Chistiakov DA, Libertini A, Kotoulas G, Volckaert F.

731 2003. Eleven new microsatellites of the sea bass (Dicentrarchus labrax L.). Molecular Ecology

732 Notes 3:352-354.

733 Vignon M, Sasal P. 2010. The use of geometric morphometrics in understanding shape

734 variability of sclerotized haptoral structures of monogeneans (Platyhelminthes) with insights into 735 biogeographic variability. Parasitology International 59: 183-191.

736 Yang L, Sado T, Vincent Hirt M, Pasco-Viel E, Arunachalam M, Li J, Wang X, Freyhof J,

737 Saitoh K, Simons AM, Miya M, He S, Mayden RL. 2015. Phylogeny and polyploidy:

738 resolving the classification of cyprinine fishes (Teleostei: Cypriniformes). Molecular

739 Phylogenetics and Evolution 85:97-116.

740 Ziętara MS, Lumme J. 2002. Speciation by host switch and adaptive radiation in a fish parasite

741 genus Gyrodactylus (Monogenea: Gyrodactylidae). Evolution 56:2445-2458.

742 


\section{Table 1 (on next page)}

List of hosts and their sampling localities. 


\begin{tabular}{llll}
\hline Host species & Locality name and number & River Basin & Coordinates \\
\hline Carasobarbus fritschii & Ksob River (1) & Ksob & $31^{\circ} 27^{\prime} 50.7^{\prime \prime} \mathrm{N}, 9^{\circ} 45^{\prime} 25.3^{\prime \prime} \mathrm{W}$ \\
& Chbouka River (2) & Oum Er'Rabia & $32^{\circ} 51^{\prime} 32.9^{\prime \prime} \mathrm{N}, 5^{\circ} 37^{\prime} 18.9^{\prime \prime} \mathrm{W}$ \\
& Lahdar River (6) & Sebou & $34^{\circ} 15^{\prime} 30.1^{\prime \prime} \mathrm{N}, 4^{\circ} 03^{\prime} 52.1^{\prime \prime} \mathrm{W}$ \\
Luciobarbus ksibii & Ksob River (1) & Ksob & $31^{\circ} 27^{\prime} 50.7^{\prime \prime} \mathrm{N}, 9^{\circ} 45^{\prime} 25.3^{\prime \prime} \mathrm{W}$ \\
& Chbouka River (2) & Oum Er'Rabia & $32^{\circ} 51^{\prime} 32.9^{\prime \prime} \mathrm{N}, 5^{\circ} 37^{\prime} 18.9^{\prime \prime} \mathrm{W}$ \\
Luciobarbus lepineyi & Zouala Oasis (7) & Ziz, Guir and Ghéris & $31^{\circ} 47^{\prime} 31.9^{\prime \prime} \mathrm{N}, 4^{\circ} 14^{\prime} 43.5^{\prime \prime} \mathrm{W}$ \\
Luciobarbus rabatensis & Grou River (5) & Bouregreg & $33^{\circ} 35^{\prime} 28.1^{\prime \prime} \mathrm{N}, 6^{\circ} 25^{\prime} 43.7^{\prime \prime} \mathrm{W}$ \\
\multirow{2}{*}{ Pterocapoeta maroccana } & Oum Er'Rabia River (El Borj) (3) & Oum Er'Rabia & $33^{\circ} 00^{\prime} 58.7^{\prime \prime} \mathrm{N}, 5^{\circ} 37^{\prime} 48.6^{\prime \prime} \mathrm{W}$ \\
\hline
\end{tabular}

1

2 


\section{Table 2 (on next page)}

List of Dactylogyrus species used in this study with their host species, localities of sampling, specimens deposited (HEL = MNHN; $M=$ IPCAS), and GenBank accession numbers (*present study).

Numbers of localities correspond to those in Fig. 1. 


\begin{tabular}{|c|c|c|c|c|c|c|}
\hline \multirow{2}{*}{ Dactylogyrus spp. } & \multirow{2}{*}{ Host species } & \multirow{2}{*}{ Locality } & \multicolumn{2}{|c|}{ Specimens deposited } & \multicolumn{2}{|c|}{ GenBank ID } \\
\hline & & & Vouchers & Hologenophores & $28 \mathrm{~S}$ & $18 S+$ ITS1 \\
\hline \multirow[t]{2}{*}{ D. borjensis } & L. zayanensis & El Borj (3) & HEL1265-1267 & HEL1268, 1269 & MN973819 & MN974257 \\
\hline & & Dar Oulad Zidouh (4) & M-752 & & & \\
\hline D. draaensis & L. lepiney & Zouala Oasis (7) & HEL1351, 1352 & & MN973816 & MN974258 \\
\hline D. ksibii 1 & L. ksibi & Ksob River (1) & HEL1260 & HEL1262 & MN973812 & MN974252 \\
\hline D. ksibii 2 & $L . k s i b i$ & Chbouka River (2) & HEL1261 & HEL1263 & MN973811 & MN974251 \\
\hline D. ksibii 3 & L. rabatensis & Grou River (5) & M-751 & HEL1264/ M-751 & MN973817 & MN974250 \\
\hline \multirow[t]{5}{*}{ D. marocanus } & C. fritschii & Chbouka River (2) & M-750 & M-750 & & KY629333 \\
\hline & & Ksob River (1) & M-750 & M-750 & KY629355 & \\
\hline & L. ksibi & Chbouka River (2) & M-750 & M-750 & MW218580* & MW218673* \\
\hline & L. zayanensis & El Borj (3) & HEL1255, 1267 & HEL1258, 1259/ M-750 & MW218669* & MW218671* \\
\hline & P. maroccana & El Borj (3) & HEL1256, 1257 & M-750 & MW218579* & MW218672* \\
\hline
\end{tabular}

1 


\section{Table 3(on next page)}

Uncorrected pairwise genetic distances between Moroccan species of Dactylogyrus. 


\begin{tabular}{lllllllllllll}
\hline Dactylogyrus spp. & $\mathbf{1}$ & $\mathbf{2}$ & $\mathbf{3}$ & $\mathbf{4}$ & $\mathbf{5}$ & $\mathbf{6}$ & $\mathbf{7}$ & $\mathbf{8}$ & $\mathbf{9}$ & $\mathbf{1 0}$ & $\mathbf{1 1}$ \\
\hline $\mathbf{2 8 S}$ rDNA & & & & & & & & & & & \\
1 & D. borjensis & & & & & & & & & & & \\
2 & D. atlasensis & 0.013 & & & & & & & & & & \\
3 & D. benhoussai & 0.015 & 0.018 & & & & & & & & & \\
4 & D. draaensis & 0.026 & 0.031 & 0.031 & & & & & & & & \\
5 & D. scorpius & 0.019 & 0.019 & 0.012 & 0.035 & & & & & & & \\
6 & D. falsiphallus & 0.015 & 0.010 & 0.021 & 0.034 & 0.021 & & & & & & \\
7 & D. ksibii 1 & 0.022 & 0.024 & 0.012 & 0.035 & 0.015 & 0.026 & & & & & \\
8 & D. ksibii 2 & 0.022 & 0.024 & 0.012 & 0.035 & 0.015 & 0.026 & 0.003 & & & & \\
9 & D. ksibii 3 & 0.022 & 0.022 & 0.009 & 0.035 & 0.013 & 0.023 & 0.005 & 0.005 & & & \\
10 & D. fimbriphallus & 0.021 & 0.026 & 0.026 & 0.015 & 0.030 & 0.028 & 0.032 & 0.032 & 0.032 & & \\
11 & D. varius & 0.019 & 0.022 & 0.004 & 0.035 & 0.015 & 0.024 & 0.015 & 0.015 & 0.013 & 0.030 & \\
12 & D. marocanus & 0.201 & 0.204 & 0.202 & 0.208 & 0.202 & 0.204 & 0.206 & 0.208 & 0.203 & 0.201 & 0.206
\end{tabular}

\section{ITS1}

$1 \quad$ D. borjensis

$2 \quad$ D. atlasensis $\quad 0.067$

$3 \quad$ D. benhoussai $\quad 0.043 \quad 0.057$

$4 \quad$ D. draaensis $\quad 0.128 \quad 0.133 \quad 0.126$

$5 \quad$ D. scorpius $\quad 0.062 \quad 0.078 \quad 0.043 \quad 0.150$

$6 \quad$ D. falsiphallus $\quad 0.036 \quad 0.071 \quad 0.050 \quad 0.126 \quad 0.064$

$7 \begin{array}{llllllll}\text { D. ksibii } 1 & 0.055 & 0.074 & 0.033 & 0.140 & 0.038 & 0.057\end{array}$

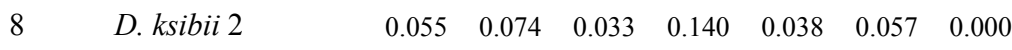

$9 \quad \begin{array}{llllllllll}\text { D. ksibii } 3 & 0.055 & 0.074 & 0.033 & 0.140 & 0.043 & 0.059 & 0.014 & 0.014\end{array}$

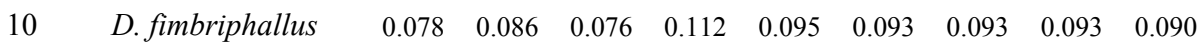

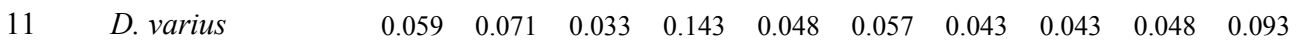

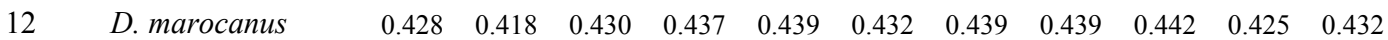

\section{S rDNA}

$\begin{array}{llllllllllllll}1 & \text { D. borjensis } & & & & & & & & & & & \\ 2 & \text { D. atlasensis } & 0.002 & & & & & & & & & \\ 3 & \text { D. benhoussai } & 0.002 & 0.004 & & & & & & & & \\ 4 & \text { D. draaensis } & 0.023 & 0.025 & 0.025 & & & & & & & \\ 5 & \text { D. scorpius } & 0.004 & 0.006 & 0.006 & 0.023 & & & & & & & \\ 6 & \text { D. falsiphallus } & 0.004 & 0.006 & 0.006 & 0.023 & 0.004 & & & & & & \\ 7 & \text { D. ksibii 1 } & 0.006 & 0.008 & 0.008 & 0.025 & 0.008 & 0.010 & & & & & \\ 8 & \text { D. ksibii 2 } & 0.006 & 0.008 & 0.008 & 0.027 & 0.010 & 0.010 & 0.000 & & & & \\ 9 & \text { D. ksibii 3 } & 0.006 & 0.008 & 0.008 & 0.025 & 0.008 & 0.010 & 0.002 & 0.002 & & & \\ 10 & \text { D. fimbriphallus } & 0.010 & 0.012 & 0.012 & 0.029 & 0.014 & 0.014 & 0.017 & 0.017 & 0.017 & & \\ 11 & \text { D. varius } & 0.000 & 0.002 & 0.002 & 0.023 & 0.004 & 0.004 & 0.004 & 0.004 & 0.006 & 0.010 \\ 12 & \text { D. marocanus } & 0.043 & 0.041 & 0.045 & 0.066 & 0.048 & 0.043 & 0.050 & 0.050 & 0.050 & 0.054 & 0.043\end{array}$

1

2

3

4 
Table 4 (on next page)

List of Dactylogyrus species, their cyprinid host species, country of collection and GenBank accession numbers for sequences used for the phylogenetic reconstruction. 


\begin{tabular}{|c|c|c|c|c|}
\hline Dactylogyrus species & Host species & Locality & 28S rDNA & $\begin{array}{l}\text { 18S rDNA } \\
\text { ITS1 }\end{array}$ \\
\hline D. andalousiensis El Gharbi, Renaud \& Lambert, 1992 & Luciobarbus sclateri (Günther) & Portugal & KY629351 & KY629331 \\
\hline D. atlasensis El Gharbi, Birgi \& Lambert, 1994 & Luciobarbus pallaryi (Pellegrin) & $\begin{array}{l}\text { Morocco (Zouala } \\
\text { Oasis) }\end{array}$ & KY629356 & KY629337 \\
\hline D. balkanicus Dupont \& Lambert, 1986 & Barbus prespensis Karaman & Albania & KY201107 & KY201093 \\
\hline D. benhoussai Rahmouni, Řehulková \& Šimková, 2017 & $\begin{array}{l}\text { Luciobarbus yahyaouii Doadrio, } \\
\text { Casal-López \& Perea }\end{array}$ & $\begin{array}{l}\text { Morocco (Melloulou } \\
\text { River) }\end{array}$ & KY553862 & KY578025 \\
\hline D. borjensis El Gharbi, Birgi \& Lambert, 1994 & $\begin{array}{l}\text { Luciobarbus zayanensis Doadrio, } \\
\text { Casal- López \& Yahyaoui }\end{array}$ & $\begin{array}{l}\text { Morocoo (Oum } \\
\text { Er'Rabia River) }\end{array}$ & MN973819 & MN974257 \\
\hline D. carpathicus Zachvatkin, 1951 & Barbus barbus (Linnaeus) & Czech Republic & KY201111 & KY201098 \\
\hline D. crivellius Dupont \& Lambert, 1986 & $\begin{array}{l}\text { Barbus peloponnesius } \\
\text { Valenciennes }\end{array}$ & Greece & KY201108 & KY629339 \\
\hline D. draaensis El Gharbi, Birgi \& Lambert, 1994 & Luciobarbus lepineyi (Pellegrin) & $\begin{array}{l}\text { Morocco (Zouala } \\
\text { Oasis) }\end{array}$ & MN973816 & MN974258 \\
\hline D. dyki Ergens \& Lucký, 1959 & Barbus barbus & Czech Republic & KY629367 & KY629338 \\
\hline D. falsiphallus Rahmouni, Řehulková \& Šimková, 2017 & $\begin{array}{l}\text { Luciobarbus maghrebensis } \\
\text { Doadrio, Perea \& Yahyaoui }\end{array}$ & $\begin{array}{l}\text { Morocco (Lahdar } \\
\text { River) }\end{array}$ & KZ553861 & KY57802 \\
\hline D. fimbriphallus El Gharbi, Birgi \& Lambert, 1994 & $\begin{array}{l}\text { Luciobarbus massaensis } \\
\text { (Pellegrin) }\end{array}$ & $\begin{array}{l}\text { Morocco (Massa } \\
\text { River) }\end{array}$ & KY629357 & KY629332 \\
\hline D. ksibii 1 El Gharbi, Birgi \& Lambert, 1994 & Luciobarbus ksibi (Boulenger) & Morocco (Ksob River) & MN973812 & MN974252 \\
\hline D. ksibii 2 & Luciobarbus ksibi & $\begin{array}{l}\text { Morocco (Chbouka } \\
\text { River) }\end{array}$ & MN973811 & MN974251 \\
\hline D. ksibii 3 & $\begin{array}{l}\text { Luciobarbus rabatensis Doadrio, } \\
\text { Perea \& Yahyaoui }\end{array}$ & Morocco (Grou River) & MN973817 & MN974250 \\
\hline D. kulindrii El Gharbi, Birgi \& Lambert, 1994 & Carasobarbus fritschii (Günther) & Morocco (Ksob River) & KY629354 & KY629336 \\
\hline D. legionensis González Lanza \& Alvarez Pellitero, 1982 & $\begin{array}{l}\text { Luciobarbus guiraonis } \\
\text { (Steindachner) }\end{array}$ & Spain & KY629350 & KY629330 \\
\hline D. linstowoides El Gharbi, Renaud \& Lambert, 1992 & Luciobarbus guiraonis & Spain & KY629349 & KY629329 \\
\hline D. malleus Linstow, 1877 & Barbus barbus & Czech Republic & KY201112 & KY201099 \\
\hline D. marocanus El Gharbi, Birgi \& Lambert, 1994 & Carasobarbus fritschii & $\begin{array}{l}\text { Morocco (Oum } \\
\text { Er'Rabia River) }\end{array}$ & KY629355 & KY629333 \\
\hline D. petenyi Kaštak, 1957 & Barbus balcanicus Kotlík & Greece & KY201113 & KY201097 \\
\hline D. prespensis Dupont \& Lambert, 1986 & Barbus prespensis & Greece & KY201110 & KY201096 \\
\hline D. remi Řehulková, Benovics \& Šimková, 2020 & $\begin{array}{l}\text { Luciobarbus graecus } \\
\text { (Steindachner) }\end{array}$ & Greece & KY201115 & KY201101 \\
\hline D. scorpius Rahmouni, Řehulková \& Šimková, 2017 & $\begin{array}{l}\text { Luciobarbus rifensis Doadrio, } \\
\text { Casal- López \& Yahyaoui }\end{array}$ & $\begin{array}{l}\text { Morocco (Loukkos } \\
\text { River) }\end{array}$ & KY553860 & KY578023 \\
\hline D. varius Rahmouni, Řehulková \& Šimková, 2017 & $\begin{array}{l}\text { Luciobarbus maghrebensis } \\
\text { Doadrio, Perea \& Yahyaoui }\end{array}$ & $\begin{array}{l}\text { Morocco (Lahdar } \\
\text { River) }\end{array}$ & KZ553863 & KY578026 \\
\hline D. volutus El Gharbi, Birgi \& Lambert, 1994 & Carasobarbus fritschii & $\begin{array}{l}\text { Morocco (Lahdar } \\
\text { River) }\end{array}$ & KY629353 & KY629334 \\
\hline D. zatensis El Gharbi, Birgi \& Lambert, 1994 & Carasobarbus fritschii & $\begin{array}{l}\text { Morocco (Oum } \\
\text { Er'Rabia River) }\end{array}$ & KY629352 & KY629335 \\
\hline \\
\hline \\
\hline & & & & \\
\hline
\end{tabular}


Figure 1

Map showing the sampling localities: 1, Ksob River; 2, Chbouka River; 3, Oum Er'Rabia (near El borj);4, Oum Er'Rabia (Dar Oulad Zidouh); 5, Grou River; 6, Lahdar River; 7 , Zouala Oasis.

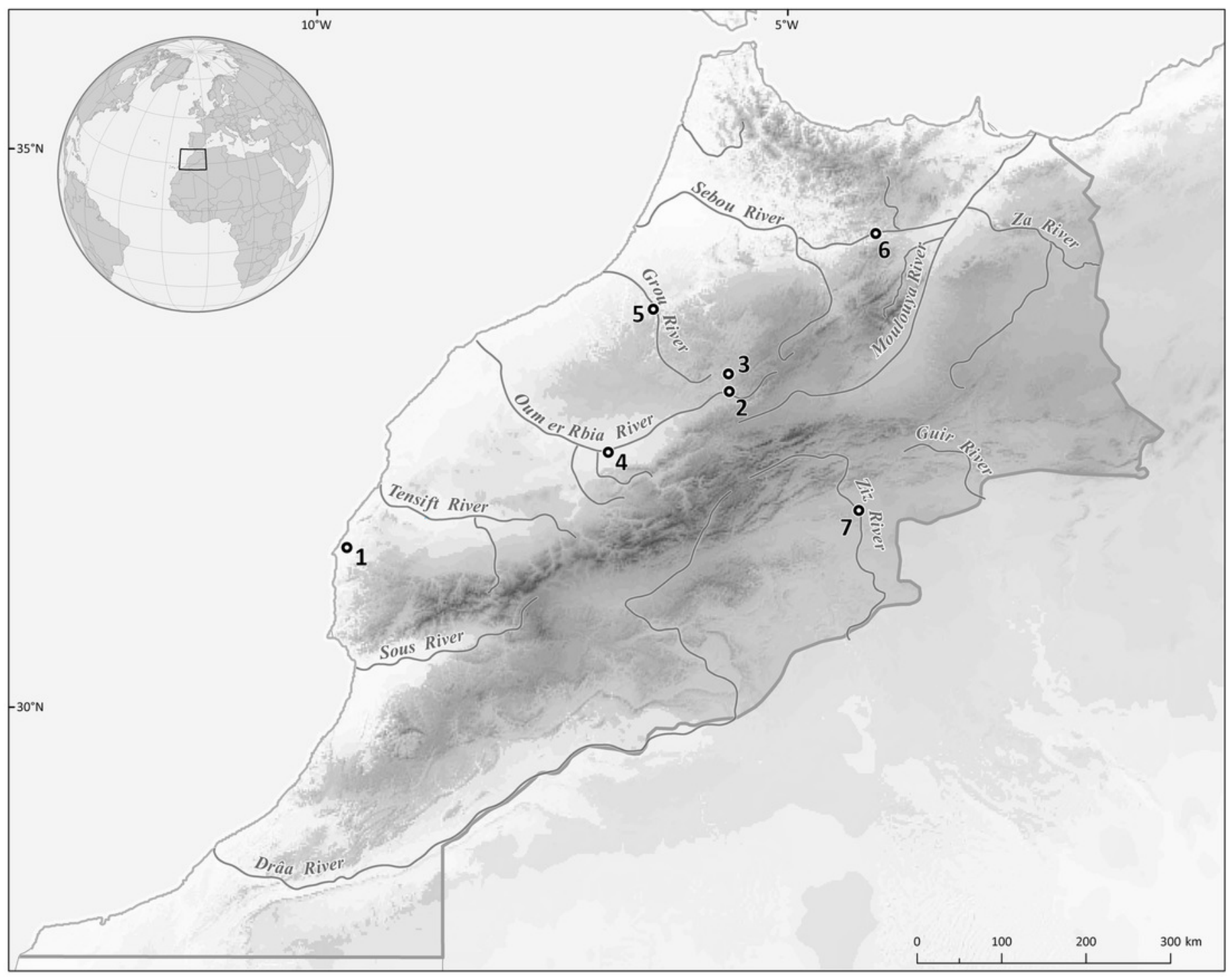


Figure 2

Sclerotized structures of Dactylogyrus marocanus ex Pterocapoeta maroccana (Oum Er'Rabia River, El Borj).

DA, dorsal anchor; DB, dorsal bar; VB, ventral bar; N, needle; I-VII, hooks (pairs I-V ventral; pairs VI, VII dorsal); MCO, male copulatory organ; VG, vagina.

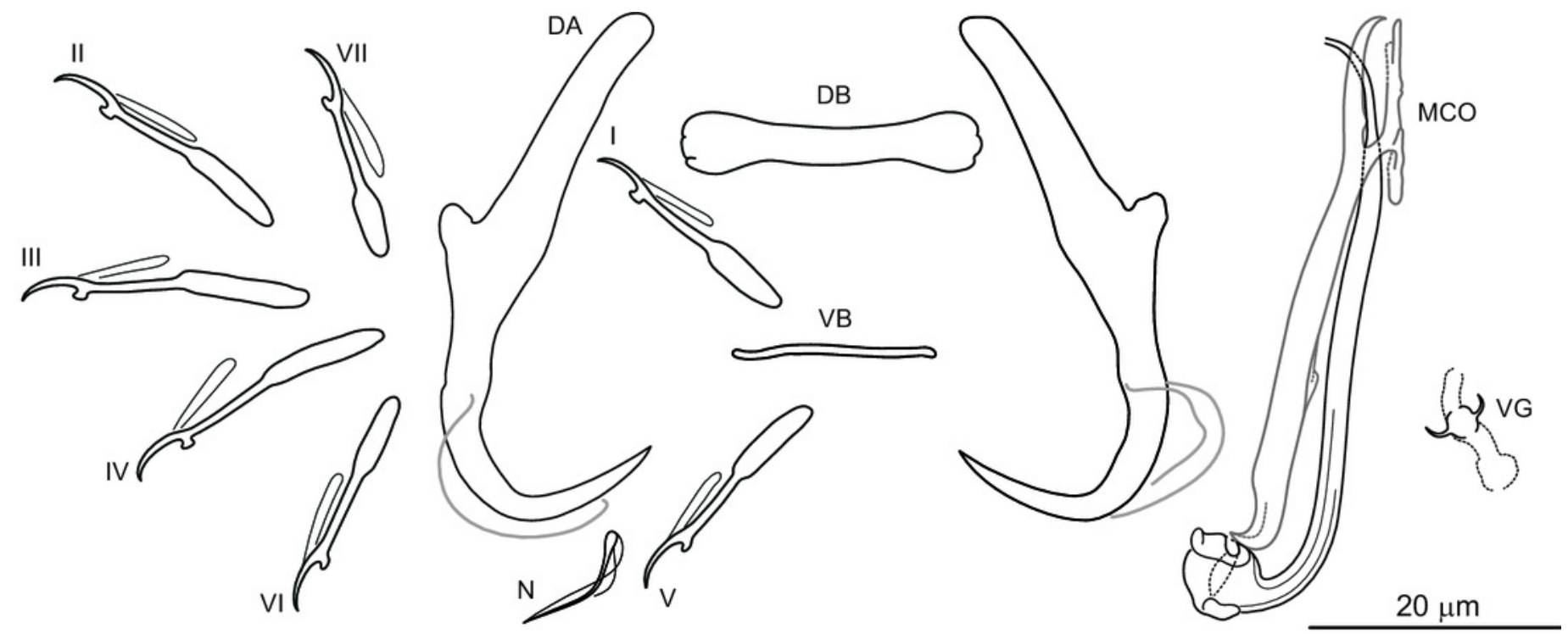


Figure 3

Sclerotized structures of Dactylogyrus ksibii ex Luciobarbus ksibi (Ksob River) (A) and L. rabatensis (Grou River) (B).

DA, dorsal anchor; DB, dorsal bar; VB, ventral bar; N, needle; I-VII, hooks (pairs I-V ventral; pairs VI, VII dorsal); MCO, male copulatory organ; VG, vagina. 

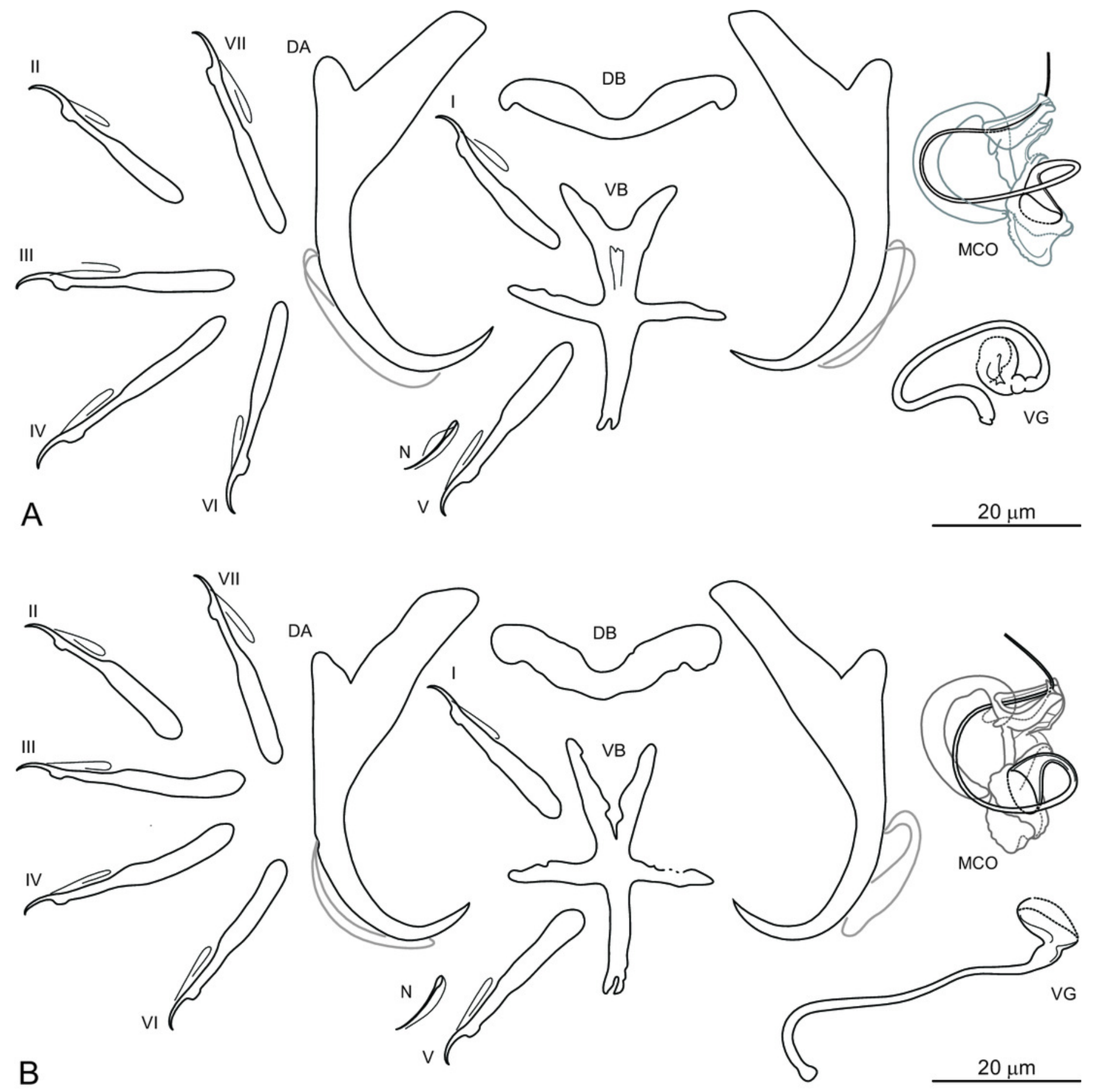
Figure 4

Sclerotized structures of Dactylogyrus borjensis ex Luciobarbus zayanensis (Oum Er'Rabia River, El Borj).

DA, dorsal anchor; DB, dorsal bar; VB, ventral bar; N, needle; I-VII, hooks (pairs I-V ventral; pairs VI, VII dorsal); MCO, male copulatory organ; VG, vagina.

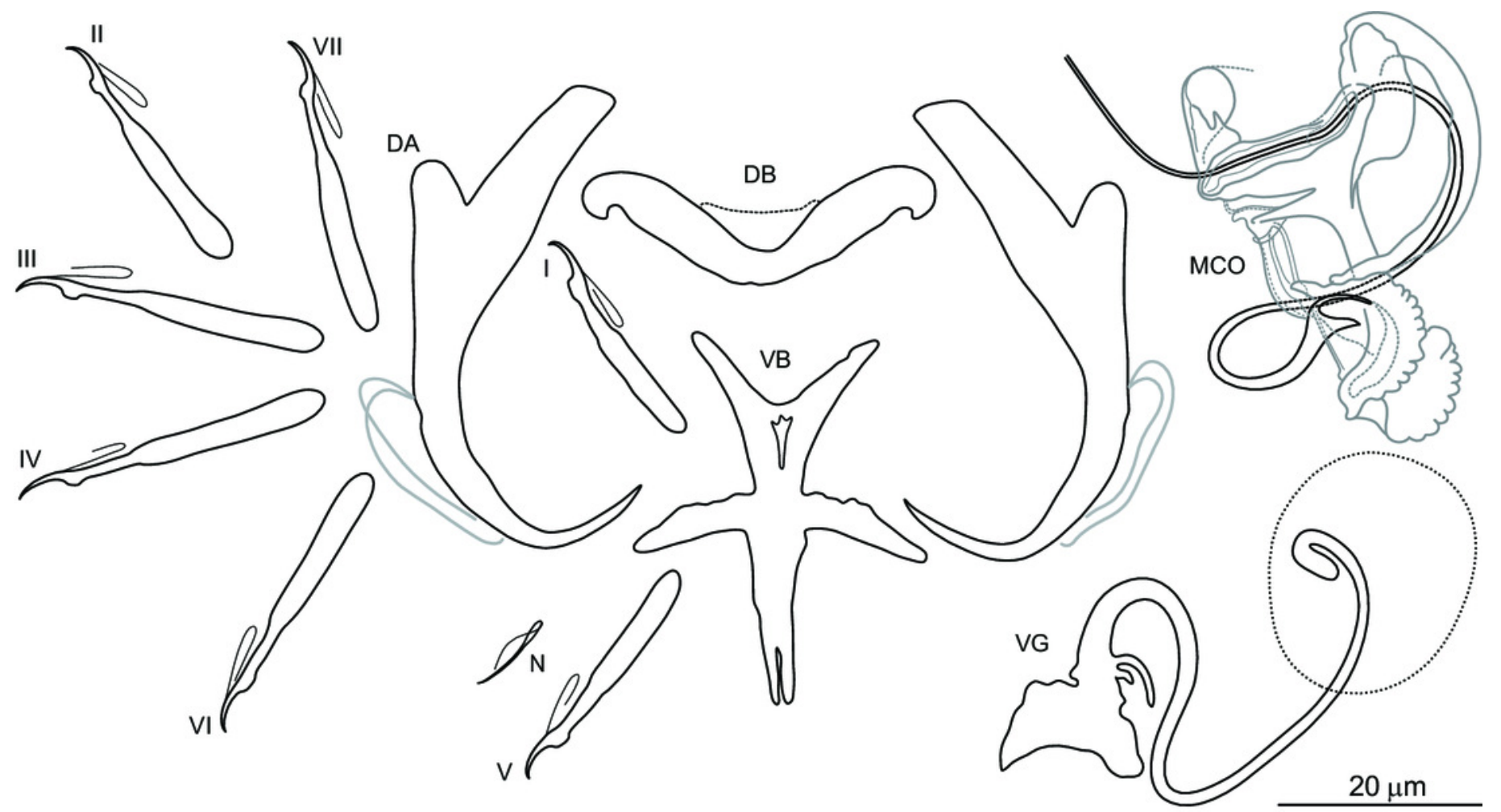


Figure 5

Sclerotized structures of Dactylogyrus draaensis ex Luciobarbus lepineyi (Zouala Oasis).

DA, dorsal anchor; DB, dorsal bar; VB, ventral bar; N, needle; I-VII, hooks (pairs I-V ventral; pairs VI, VII dorsal); MCO, male copulatory organ; VG, vagina.

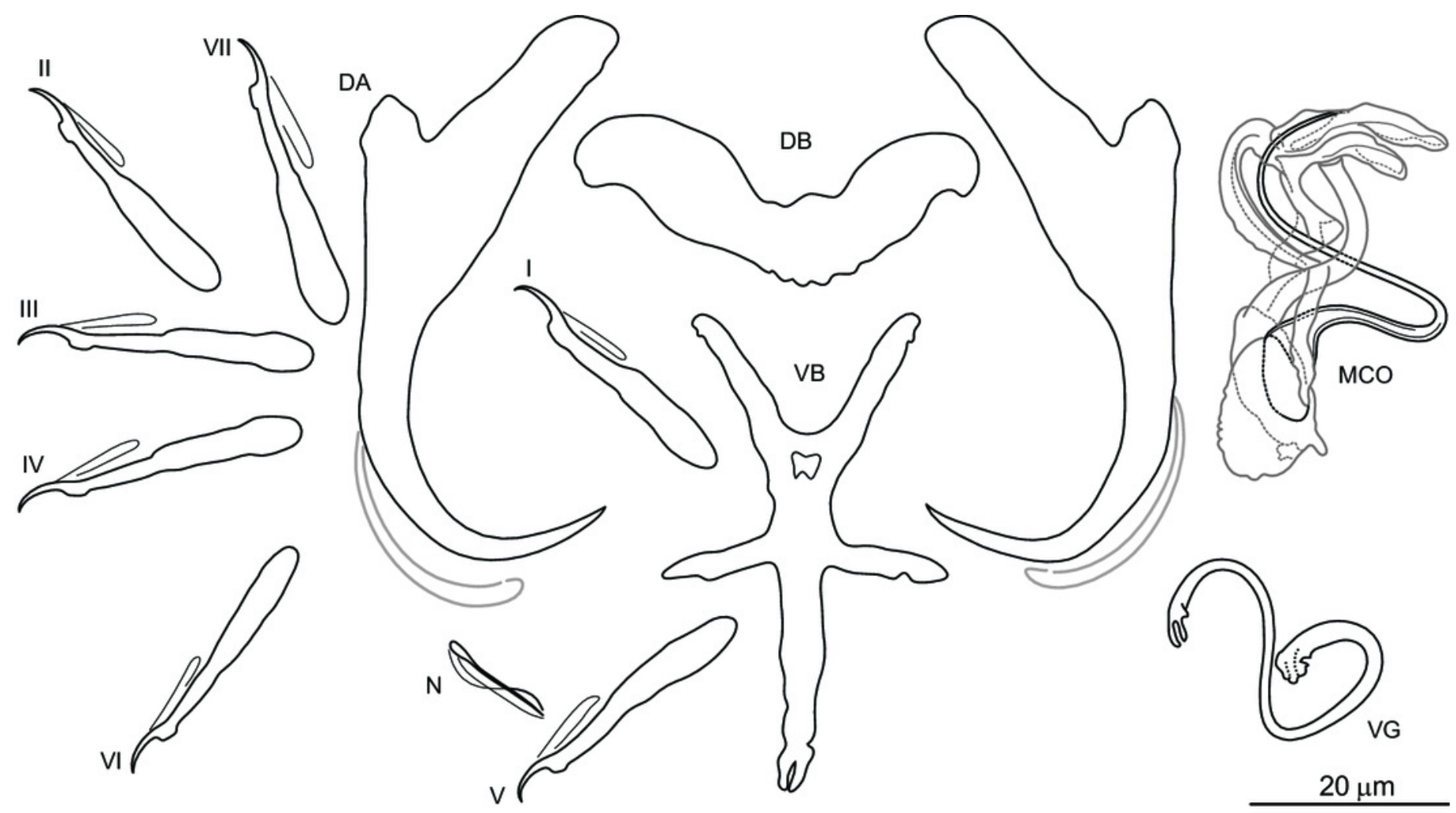




\section{Figure 6}

Phylogenetic tree constructed by $\mathrm{BI}$ analysis using combined data of partial $28 \mathrm{~S}, 18 \mathrm{~S}$ rDNA and ITS1.

Values showed at the nodes indicate posterior probabilities from BI analysis (only values

higher than 0.7 ) and bootstrap values from ML analysis (only values higher than 50 ). Dactylogyrus species parasitizing Moroccan cyprinids form three lineages, each with characteristic type of haptoral configuration: 'pseudanchoratus' type (lineage I; $D$. marocanus), 'varicorhini' type (lineage II; D. zatensis), and 'carpathicus' type (lineage III; $D$. scorpius). 


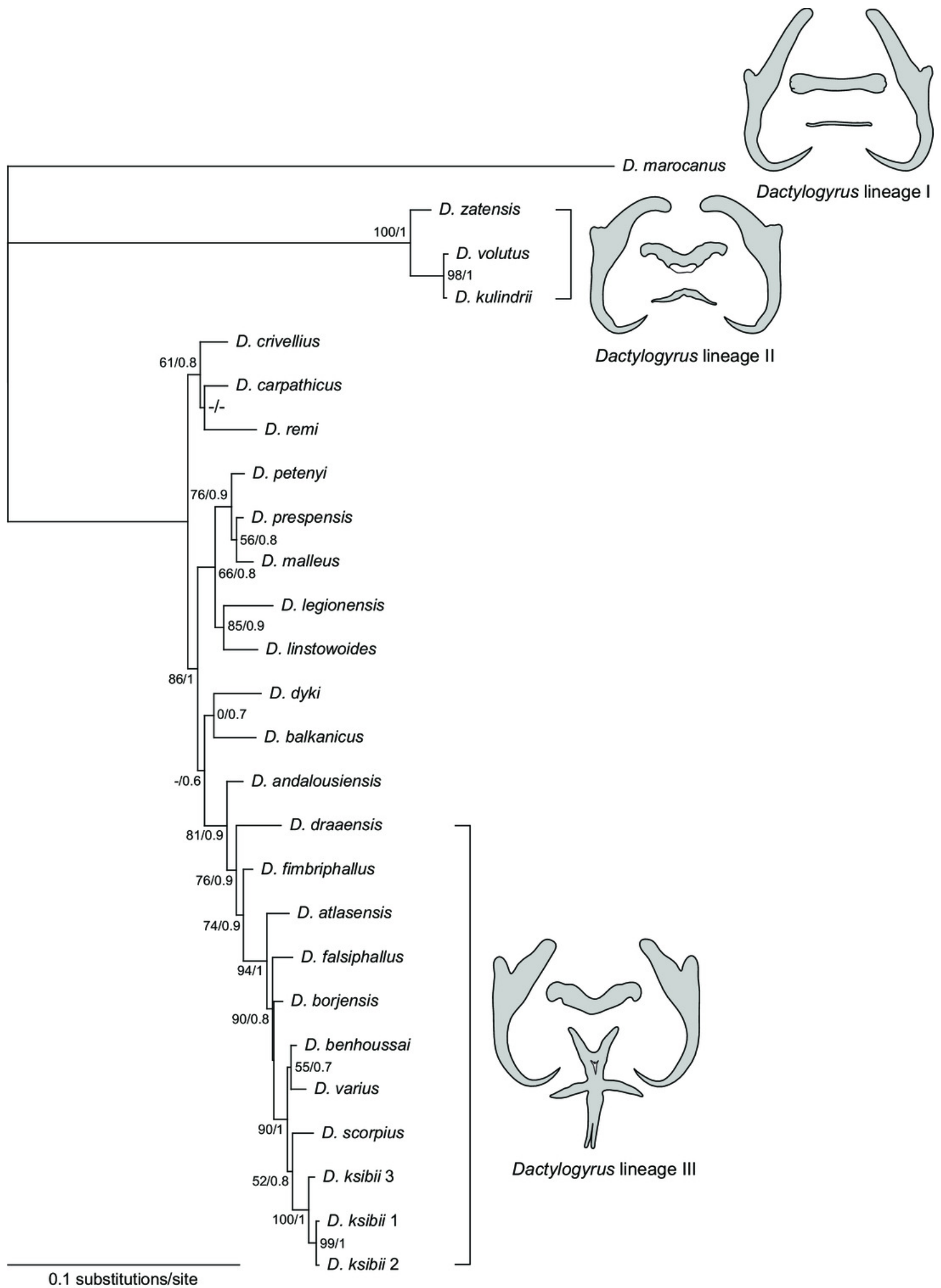

